\title{
ULF wave activity during the 2003 Halloween superstorm: multipoint observations from CHAMP, Cluster and Geotail missions
}

\author{
G. Balasis ${ }^{1}$, I. A. Daglis ${ }^{1}$, E. Zesta ${ }^{2}$, C. Papadimitriou ${ }^{1,3}$, M. Georgiou ${ }^{1,3}$, R. Haagmans ${ }^{4}$, and K. Tsinganos ${ }^{3}$ \\ ${ }^{1}$ Institute for Astronomy, Astrophysics, Space Applications and Remote Sensing, National Observatory of Athens, Greece \\ ${ }^{2}$ RVBXP, Air Force Research Laboratory, Hanscom AFB, MA, USA \\ ${ }^{3}$ Section of Astrophysics, Astronomy and Mechanics, Department of Physics, University of Athens, Greece \\ ${ }^{4}$ European Space Research and Technology Centre, European Space Agency, Noordwijk, The Netherlands
}

Correspondence to: G. Balasis (gbalasis@ noa.gr)

Received: 6 July 2011 - Revised: 26 November 2012 - Accepted: 27 November 2012 - Published: 21 December 2012

\begin{abstract}
We examine data from a topside ionosphere and two magnetospheric missions (CHAMP, Cluster and Geotail) for signatures of ultra low frequency (ULF) waves during the exceptional 2003 Halloween geospace magnetic storm, when Dst reached $\sim-380 \mathrm{nT}$. We use a suite of waveletbased algorithms, which are a subset of a tool that is being developed for the analysis of multi-instrument multi-satellite and ground-based observations to identify ULF waves and investigate their properties. Starting from the region of topside ionosphere, we first present three clear and strong signatures of Pc3 ULF wave activity (frequency $15-100 \mathrm{mHz}$ ) in CHAMP tracks. We then expand these three time intervals for purposes of comparison between CHAMP, Cluster and Geotail Pc3 observations but also to be able to search for Pc4-5 wave signatures (frequency $1-10 \mathrm{mHz}$ ) into Cluster and Geotail measurements in order to have a more complete picture of the ULF wave occurrence during the storm. Due to the fast motion through field lines in a low Earth orbit (LEO) we are able to reliably detect Pc3 (but not Pc4-5) waves from CHAMP. This is the first time, to our knowledge, that ULF wave observations from a topside ionosphere mission are compared to ULF wave observations from magnetospheric missions. Our study provides evidence for the occurrence of a number of prominent ULF wave events in the Pc3 and Pc4-5 bands during the storm and offers a platform to study the wave evolution from high altitudes to LEO. The ULF wave analysis methods presented here can be applied to observations from the upcoming Swarm multi-satellite mission of ESA, which is anticipated to enable joint studies with the Cluster mission.
\end{abstract}

Keywords. Magnetospheric physics (Magnetospheric configuration and dynamics; Plasma waves and instabilities; Storms and substorms)

\section{Introduction}

Magnetospheric ultra low frequency (ULF) waves play an important role in the overall dynamics of geospace plasmas and particularly in radiation belt dynamics (e.g., Baker and Daglis, 2007). ULF waves are large-scale phenomena, and in principle, simultaneous observations at many locations are needed to understand in depth their generation and propagation (Takahashi and Anderson, 1992). Oscillations with quasi-sinusoidal waveform are called pulsations continuous $(\mathrm{Pc})$. Those with waveforms that are more irregular are called pulsations irregular $(\mathrm{Pi})$ and are associated with magnetospheric substorms. In particular (Jacobs et al., 1964), continuous pulsations with frequencies in the range $1 \mathrm{mHz}$ to $5 \mathrm{~Hz}$, denoted as Pc1-2 (100 mHz-5 Hz), Pc3 $(20-100 \mathrm{mHz}), \mathrm{Pc} 4$ $(7-20 \mathrm{mHz})$, and Pc5 (1-7 mHz), have been extensively studied using measurements from both space-borne and groundbased instruments for many years (for a recent review see Menk, 2011). They are broadly of two types, depending on whether their energy source originates in the solar wind on the dayside or from processes within the magnetosphere (e.g., substorms and other instabilities in the magnetotail) on the nightside.

A large number of past studies employing measurements from ground magnetometers, radar and geosynchronous satellites were focused on their polarization properties, 


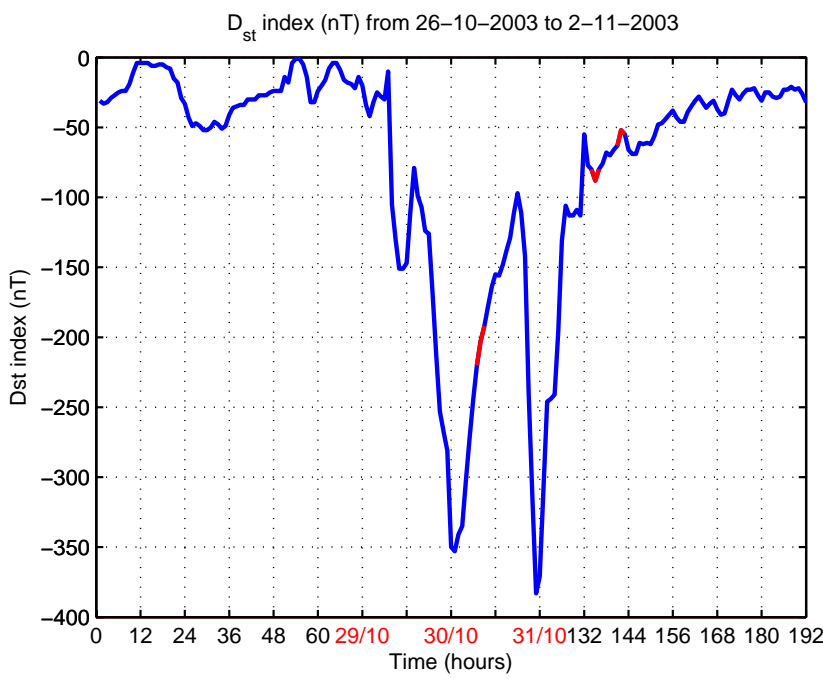

Fig. 1. The time series of Dst index from 26 October 2003 to 2 November 2003. The three days that include the storm onset, the first storm peak $(-353 \mathrm{nT})$ with the associated short recovery phase, as well as the second storm peak $(-383 \mathrm{nT})$ along with the regular recovery phase, i.e., 29, 30 and 31 October 2003, are labeled in red. Moreover, the three time intervals that Pc3 ULF wave activity was initially identified in CHAMP observations and were selected and further expanded into two-hour intervals for analysis using Cluster and Geotail measurements are marked in red.

occurrence distribution, dependence on solar wind parameters, relation to geomagnetic storms and substorms and lastly, associated particle flux modulations. These studies revealed that toroidal and poloidal mode field line resonances together with compressional Pc5 waves account for most of the observed coherent pulsations observed in the outer magnetosphere (Anderson et al., 1990).

Multipoint observations show that upstream ULF waves in the Pc3-4 bands are generated in the foreshock region and entering and propagating through the magnetosphere as compressional waves (Sakurai et al., 1999; Constantinescu et al., 2007; Heilig et al., 2007; Clausen et al., 2009).

Externally excited ULF waves are intimately related to shear instabilities at the dawn and dusk flanks of the magnetopause (Engebretson et al., 1998) or driven by quasiperiodic variations of the solar wind dynamic pressure on the dayside magnetopause (Kepko et al., 2002). Solar wind upstream waves may also directly enter near the equatorial noon subsolar point or the high latitude cusp regions (Kessel et al., 2004, and references therein). ULF wave excitation is also caused by sudden impulses (solar wind pressure pulses) on the magnetosphere (Southwood and Kivelson, 1990; Zong et al., 2009; Sarris et al., 2010).

In particular, observations of ULF waves with discrete frequencies of $1.3 \mathrm{mHz}, 1.9 \mathrm{mHz}, 2.8 \mathrm{mHz}$ and $3.4 \mathrm{mHz}$ provide evidence for the existence of magnetohydrodynamic (MHD) waveguide or cavity modes in the magnetosphere (Samson et al., 1992; Lee et al., 2007). The characteristic frequencies of ULF waves have been, however, found to be widely distributed, suggesting the existence of alternative sources from which they draw their energy.

Low-frequency instabilities of the ring current plasma during periods of intense geomagnetic activity are closely related with waves observed during geomagnetic storms (Ukhorskiy et al., 2009). The drift and bounce motions of energetic particles of the ring current may lead to fluctuations of electric and magnetic fields in the magnetosphere and ionosphere in the case of excess available energy (Baddeley et al., 2002).

The ULF wave characteristics vary throughout the magnetosphere because the geomagnetic field and magnetospheric plasma are strongly inhomogeneous on the wavelength scale of these waves. Magnetospheric ULF waves are spatially constrained by the magnetopause, which defines the boundaries of the magnetosphere, as well as by the extent of the plasmasphere and ionosphere.

Moreover, inhomogeneities limit the accessibility of ULF waves to particular regions of the magnetosphere. For instance, the ratio of plasma density on the two sides of the plasmapause, separating the cold dense plasma in the inner magnetosphere and the hot low-density in the outer magnetosphere, can be larger than a factor of 100 (Dent et al., 2006).

Furthermore, the frequency of ULF waves propagating through the magnetosphere is determined by the plasma composition. Enhanced populations of heavy ions $\left(\mathrm{He}^{+}\right.$and $\left.\mathrm{O}^{+}\right)$, which have been observed during magnetospheric substorms (e.g., Daglis et al., 1994; Daglis and Axford, 1996) and, especially, during geospace magnetic storms (e.g., Daglis, 1997) have a profound effect on the wave resonant frequency and harmonics (e.g., Thorne and Horne, 1997). Unlike the case of an $\mathrm{O}^{+}$ions torus, a steep plasmapause observed in the $\mathrm{He}^{+}$ ions is followed by an increase in the ULF wave resonance frequency (Fraser et al., 2005).

The Halloween 2003 magnetic storm (29 October 200331 October 2003) was a rare event that caused an extreme distortion of the outer Van Allen radiation belt (Baker et al., 2004), which was depleted and then re-formed closer to the Earth. This event offered a unique opportunity to study the wave-particle interactions in the radiation belts (Horne et al., 2005; Loto' aniu et al., 2006) and provided an ideal set of conditions to examine magnetospheric/ionospheric responses to solar wind (Harnett et al., 2008). The Halloween 2003 magnetic storm had a double peak (see the Dst index plot from 27 to 31 October 2003 in Fig. 1) and it was associated with two coronal mass ejections (CMEs) that took place on 28 and 29 October 2003, respectively.

Herein, we analyze magnetic field measurements recorded on 30 and 31 October 2003 by the low Earth orbit (LEO) CHAMP satellite, and the Cluster and Geotail spacecraft.

Starting from CHAMP data and using a wavelet analysis technique, we present three representative intervals with clear ULF wave signatures in the Pc3 frequency band. For these time intervals, we also present corresponding 
observations from Cluster and Geotail. The simultaneous occurrence of Pc3 waves at various satellites offers a useful platform to study the wave occurrence and evolution from high altitude observations to LEO, and from the outer magnetosphere to the topside ionosphere. We also study the occurrence of Pc4-5 waves in the Cluster and Geotail locations throughout the storm. The results of our approach, combining observations from a LEO satellite with magnetospheric multi-satellite missions, demonstrates the applicability of our methods to data of the upcoming Swarm three-satellite constellation of ESA. Swarm is the first LEO multi-satellite mission to study the near-Earth electromagnetic environment.

\section{Data analysis based on wavelet transforms}

ULF waves have been traditionally identified through visual inspection of series of spectrograms based on the Fast Fourier Transform (FFT). Motivated by the continuously increasing amount of data collected by space missions and groundbased instruments, algorithms have been developed based on FFT spectra to automatically examine spectrograms and identify ULF waves. Therefore, a variety of automated FFT routines exist (Anderson et al., 1992; Loto'aniu et al., 2005; Bortnik et al., 2007).

Since the 1990s, the wavelet spectral analysis has become popular, as it allows the quantitative monitoring of localized variations of power within the time series data (for example, Alexandrescu et al., 1996; Balasis et al., 2005, 2006; Balasis and Mandea, 2007). Furthermore, Heilig et al. (2007) developed an algorithm for the selection of possible ULF waverelated pulsation events from both ground and space magnetometer data. Other examples of the application of wavelets (continuous and discrete) to space data can be found, for instance, in Nose et al. (1998) and Murphy et al. (2009).

In some way, the wavelet transform is a generalized form of the Fourier transform. The main difference of wavelets is that the temporally confined basis functions used in the wavelet transform to decompose a time series can be stretched with a flexible resolution in both frequency and time. They narrow while focusing on high-frequency components and widen while searching for the low-frequency background. Thus, the frequency range of the analyzing wavelets corresponds to the spectral content of time series components (Torrence and Compo, 1998).

The wavelet transform can be superior to the Fourier spectral analysis when the spectral properties of transient, impulsive, short-lived or non-stationary signals need to be analyzed. While the Fourier transform provides fixed frequency resolution and is well suited for the representation of a continuous, long-lasting signal, the wavelet analysis can provide sufficient frequency resolution to a continuous wave band at the lower frequency range of the wavelet window, and better time resolution at the higher-frequency band of the wavelet window at the expense of frequency resolution. If the nature of the investigated signal is well known in advance, one can judiciously select either the Fourier or wavelet transform for the better representation and analysis of the signal in the frequency domain. However, when it is necessary to search for either continuous or impulsive signals and the nature of the signal is not a priori known, then a wavelet transform is more appropriate, particularly if the frequency band being investigated is carefully placed in the middle range of the wavelet frequency range so that both time and frequency resolution are carefully balanced. Our goal of investigating ULF waves on the ground and in space, which can be continuous, impulsive, stationary or propagating, points to the wavelet as the most appropriate spectral analysis technique for the search and investigation, particularly in the form of an automated tool.

It is therefore not surprising that wavelet analysis is becoming a common tool for analyzing localized variations of power within a time series. By decomposing a time series into time-frequency space, one is able to determine both the dominant modes of variability and how those modes vary in time. The advantage of analyzing a signal with wavelets as the analyzing kernel is that it enables one to study features of the signal locally with a detail matched to their scale.

Balasis et al. (2005) performed wavelet spectral analysis of magnetic field magnitude data derived from CHAMP $1 \mathrm{~Hz}$ vector fluxgate magnetometer (FGM) measurements, covering a period of approximately three years (August 2000May 2003). The wavelet spectral analysis of CHAMP data proved to be capable of detecting, identifying and classifying artificial noise sources, such as instrument problems and pre-processing errors, as well as high frequency natural signals of external fields, including ionospheric plasma bubbles and magnetospheric ULF waves.

Furthermore, Balasis and Mandea (2007) successfully used the same technique to look at CHAMP satellite data from 2004 to 2005 for ULF wave activity a few days before and after the great Sumatran earthquakes on 26 December 2004 with a magnitude of 9.3 and 28 March 2005 with a magnitude of 8.7. The same wavelet tools have been applied by Mandea and Balasis (2006) to satellite magnetic data with the aim to investigate the effects of a giant flare from magnetar SGR 1806-20 on the near-Earth electromagnetic environment, thus showing remarkable applicability to the delineation of fine electromagnetic structures contained within geophysical signals. There are several parameters of the wavelet transform, such as frequency range, power spectral density amplification factor, which need to be correctly adjusted in order to capture different kind of anomalous signals. In our present study, we apply the same values determined by Balasis and Mandea (2007) for tuning the wavelet transform.

Specifically, we use the continuous wavelet transform with the Morlet wavelet as the basis function on magnetic field measurements from the LEO satellite CHAMP, the 


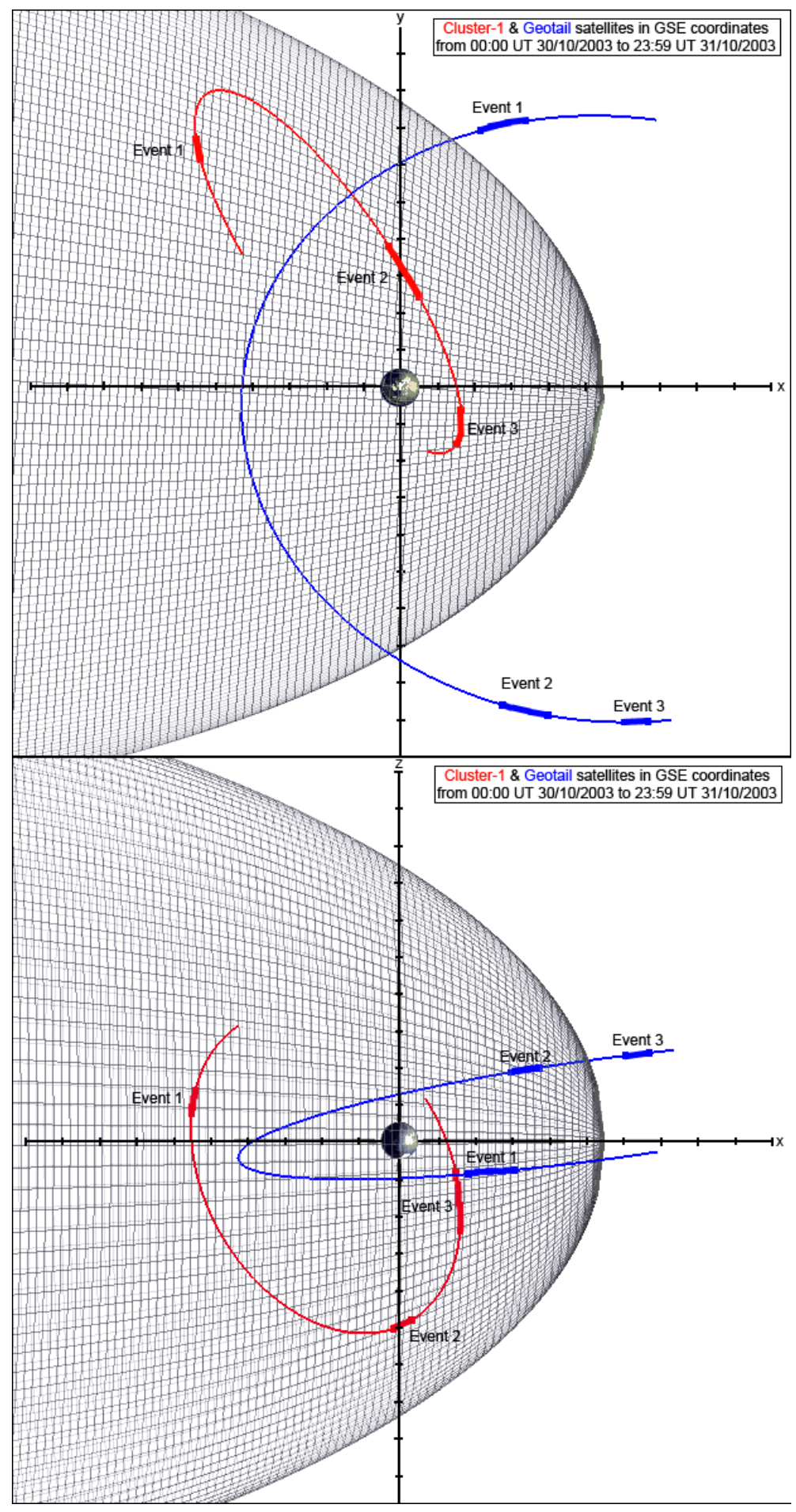

Fig. 2. The Cluster-1 and Geotail locations in GSE coordinates on the xy-plane (upper part) and on the xz-plane (lower part) for 30 and 31 October 2003. The three events discussed in this paper are also marked. (These plots are modified versions of the graphs derived by the Tool for Interactive Plotting, Sonification, and 3-D Orbit Display - TIPSOD provided by NASA.)

multi-spacecraft Cluster mission and the Geotail satellite surveying the outer magnetosphere.
We use a Mean Field-Aligned (MFA) coordinate system in the analysis of the satellite observations in order to separate ULF field variations perpendicular to, as well as along the 

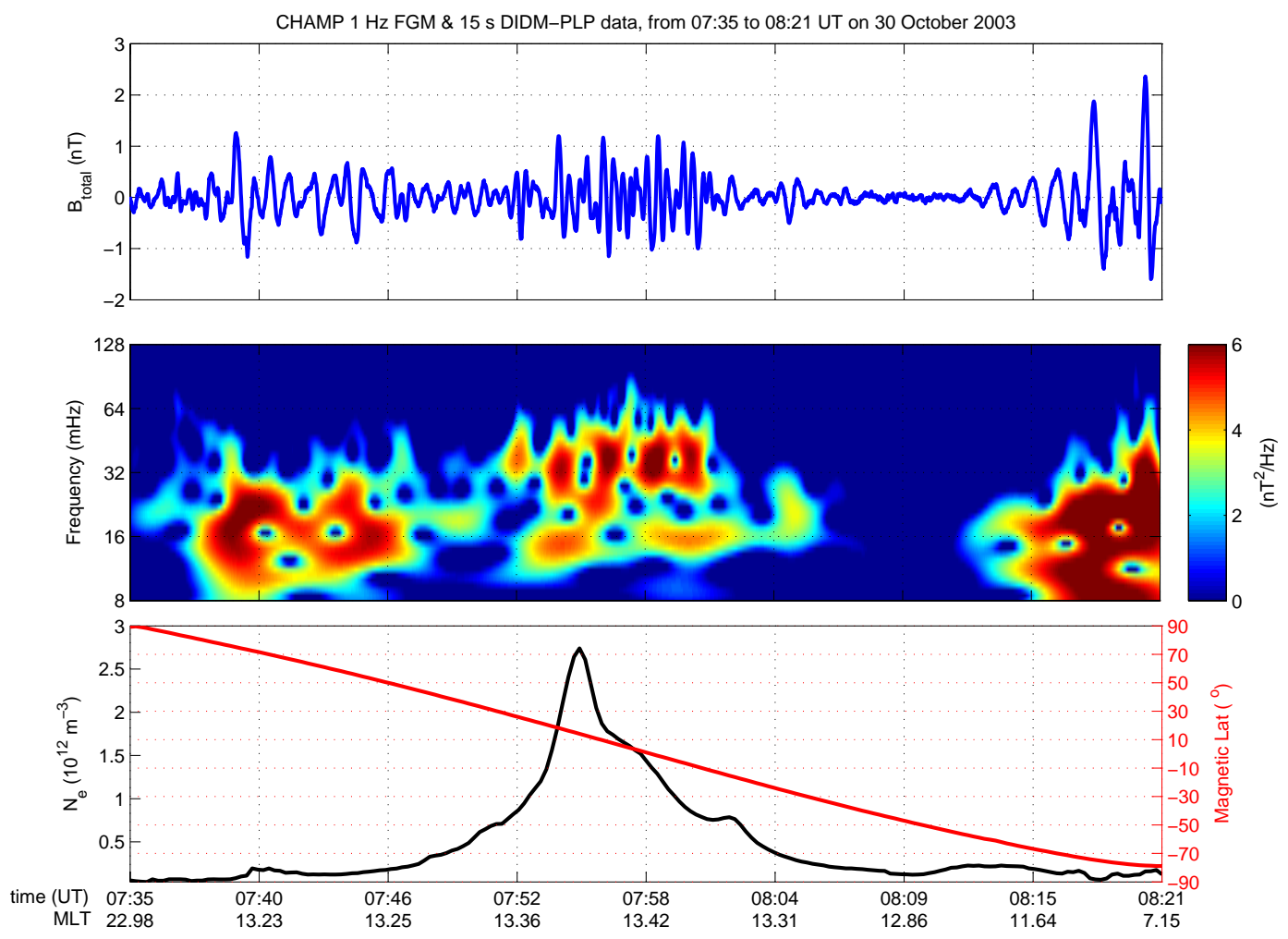

Fig. 3. The CHAMP track from 07:35 to 08:21 UT on 30 October 2003. From top to bottom are shown the time series of the CHAMP total magnetic field, calculated from the $1 \mathrm{~Hz}$ FGM data after applying a $16 \mathrm{mHz}$ high-pass filter, its corresponding wavelet power spectrum as well as the temporal variation of the CHAMP electron density data along with its magnetic latitudinal dependence, indicating that the satellite was moving from the North to the South Pole. The corresponding MLT values are also given at the bottom of the graph. A prominent Pc3 ULF wave is observed starting at around 07:52 UT and lasting $\sim 15 \mathrm{~min}$. The strong ionospheric currents' signatures near the poles that cover lower frequencies can also be seen in this plot.

magnetic field direction. The unit vectors of the MFA coordinate system are defined as follows: the parallel component in the coordinate system, $\hat{p}$, is obtained from a 20 -min running average of the instantaneous magnetic field. The other components are then chosen to be $\hat{\varphi}=(\hat{p} \times \boldsymbol{R}) /|\hat{p} \times \boldsymbol{R}|$, where $\boldsymbol{R}$ is the radius vector of the satellite, and $\hat{r}=\hat{\varphi} \times \hat{p}$. Thus, $\hat{\varphi}$ is the azimuthal component and is positive eastward, while $\hat{r}$, completing the orthogonal system is meridional and points radially outward at the magnetic equator.

ULF waves in the $\hat{p}, \hat{\varphi}$ and $\hat{r}$ directions are referred to as compressional, toroidal and poloidal, respectively. It should be noted that the average magnetic field has been subtracted from the projection of the magnetic field onto the average unit vector $\hat{p}$. The 20 -min running average applied to the field during coordinate rotation acts as a high-pass filter.

Nonetheless, in the case of the standard transformation of LEO satellite measurements into an Earth-oriented frame adds undesirable attitude noise to the data (Heilig et al., 2007); thus, generating clean vector data requires a lot of manual intervention. However, as the compressional (fieldaligned) component dominates over the transverse components, the wave signature can well be derived from the total field variations for a LEO satellite (Jadhav et al., 2001; Heilig et al., 2007). Therefore, CHAMP total magnetic field can be considered a fairly good approximation of its compressional component for studying ULF waves.

\section{Observations}

The solar activity in the end of October 2003 initiated a series of intense magnetospheric disturbances during two successive deep reductions of the Dst index (see Fig. 1) as two consecutive CMEs impacted the Earth's magnetosphere. In Fig. 1, the three days that include the storm onset, the first storm peak $(-353 \mathrm{nT})$ with the associated short recovery phase as well as the second storm peak $(-383 \mathrm{nT})$ along with the regular recovery phase, i.e., 29,30 and 31 October 2003, are labeled in red. The "Halloween" storm, 2931 October 2003, has received considerable interest and analysis from both ground and space instrumentation, as it offers a great opportunity of understanding the response of the magnetosphere-ionosphere system to strong and continuous driving. During the Halloween storm, Geotail enters the magnetosphere on the dusk side and orbits around the nightside of 

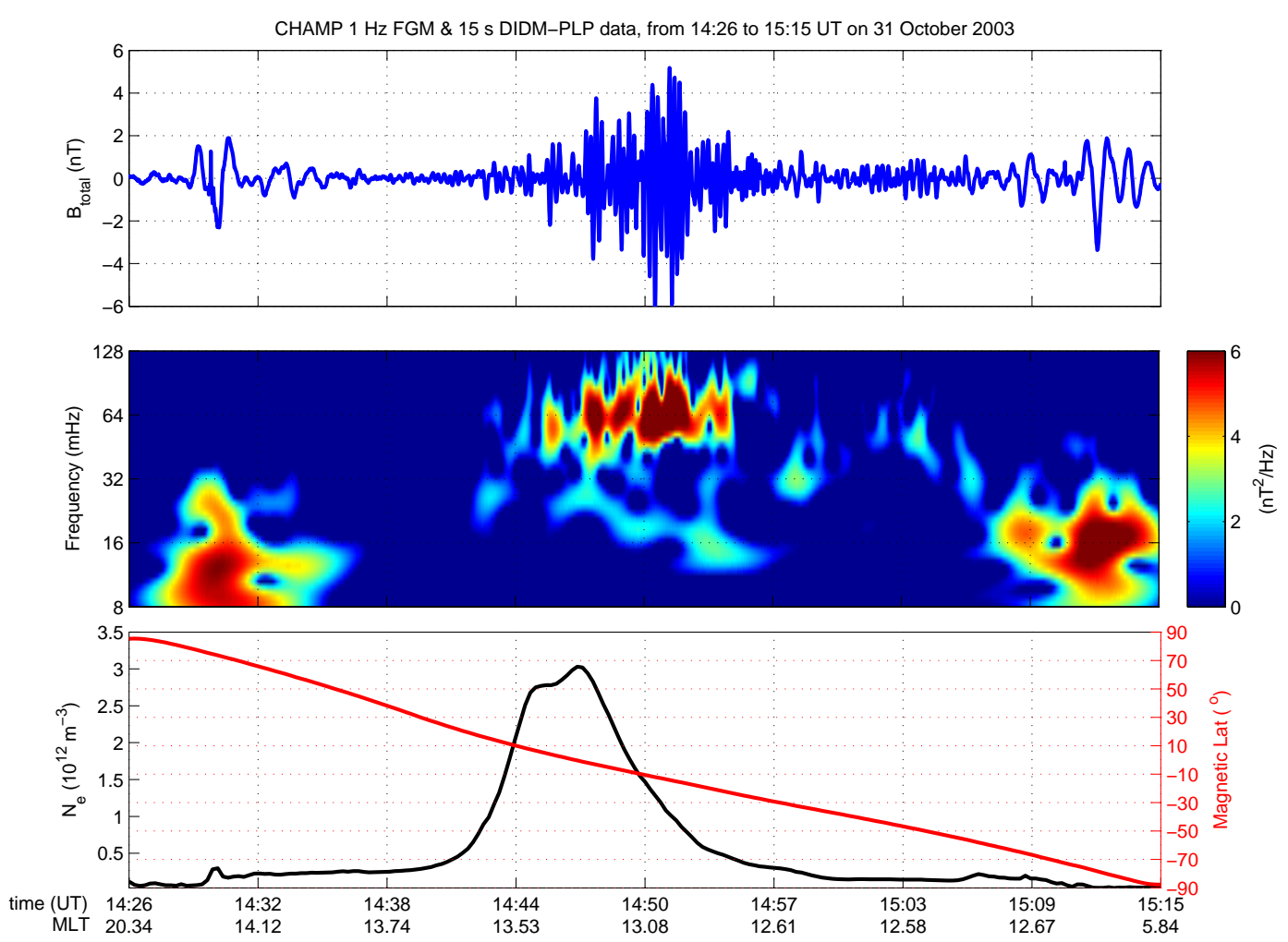

Fig. 4. The CHAMP track from 14:26 to 15:15 UT on 31 October 2003. From top to bottom are shown the time series of the CHAMP total magnetic field, calculated from the $1 \mathrm{~Hz}$ FGM data after applying a $16 \mathrm{mHz}$ high-pass filter, its corresponding wavelet power spectrum as well as the temporal variation of the CHAMP electron density data along with its magnetic latitudinal dependence indicating that the satellite was moving from the north to the south pole. The corresponding MLT values are also given at the bottom of the graph. A prominent Pc3 ULF wave is observed starting at around 14:44 UT and lasting $\sim 15 \mathrm{~min}$. The strong ionospheric currents' signatures near the poles covering lower frequencies can also be seen in this plot.

the magnetosphere near the equatorial plane, while Cluster's orbit has its apogee far off the equatorial plane on the dusk Northern Hemisphere of the magnetosphere. In Fig. 2 the locations of Cluster-1 and Geotail satellites in the Geocentric Solar Ecliptic (GSE) coordinate system and for the xy- and xz-planes are shown from 00:00 UT on 30 October 2003 to 23:59 UT on 31 October 2003.

Herein, we study the ULF wave activity that accompanied the Halloween storm using observations obtained by a topside ionosphere mission and two magnetospheric missions, whereas previous ULF wave observations made by a LEO mission have only been compared to ground measurements (e.g., Heilig et al., 2007).

In this section we start our analysis from the region of topside ionosphere. We first present three clear and strong signatures of Pc3 ULF wave activity (frequency $15-100 \mathrm{mHz}$ ) found by examining the tracks of the CHAMP satellite. The CHAMP track represents the satellite's half-orbit as it moves from one pole to another and lasts approximately $45 \mathrm{~min}$. We then expand these three time intervals in order to have a twohour duration for purposes of comparison between CHAMP, Cluster and Geotail Pc3 observations but also to be able to search for Pc4-5 wave signatures (frequency $1-10 \mathrm{mHz}$ ) into Cluster and Geotail measurements associated with the Halloween storm. Due to the fast motion through field lines in a LEO orbit we are able to reliably detect Pc3 (but not Pc4-5) waves from CHAMP.

The CHAMP satellite was launched in July 2000 into an almost circular, near-polar orbit with a period of $94 \mathrm{~min}$ and an initial altitude of $454 \mathrm{~km}$ (Reigber et al., 2005). The intense solar activity of solar cycle 23 had degraded the orbit altitude to $\sim 400 \mathrm{~km}$ at the time of the Halloween storm, in October 2003. CHAMP re-entry occurred in 2010. The low Earth orbit of CHAMP allows a global view of the topside ionosphere within the relatively short time of a full orbit.

Cluster, which consists of four identical spacecraft flying in a tetrahedral configuration (Escoubet et al., 1997), was launched in 2000 with the aim to investigate the Earth's magnetic environment at multiple scales. The four Cluster spacecraft, therefore, represent a valuable tool for the analysis of magnetospheric ULF pulsations, as shown by a plethora of recent studies (e.g., Eriksson et al., 2005; Schäfer et al., 2007; Clausen et al., 2009). For this purpose, the Cluster spacecraft were originally placed in a $4 \times 19.6 R_{\mathrm{E}}$ elliptical polar 

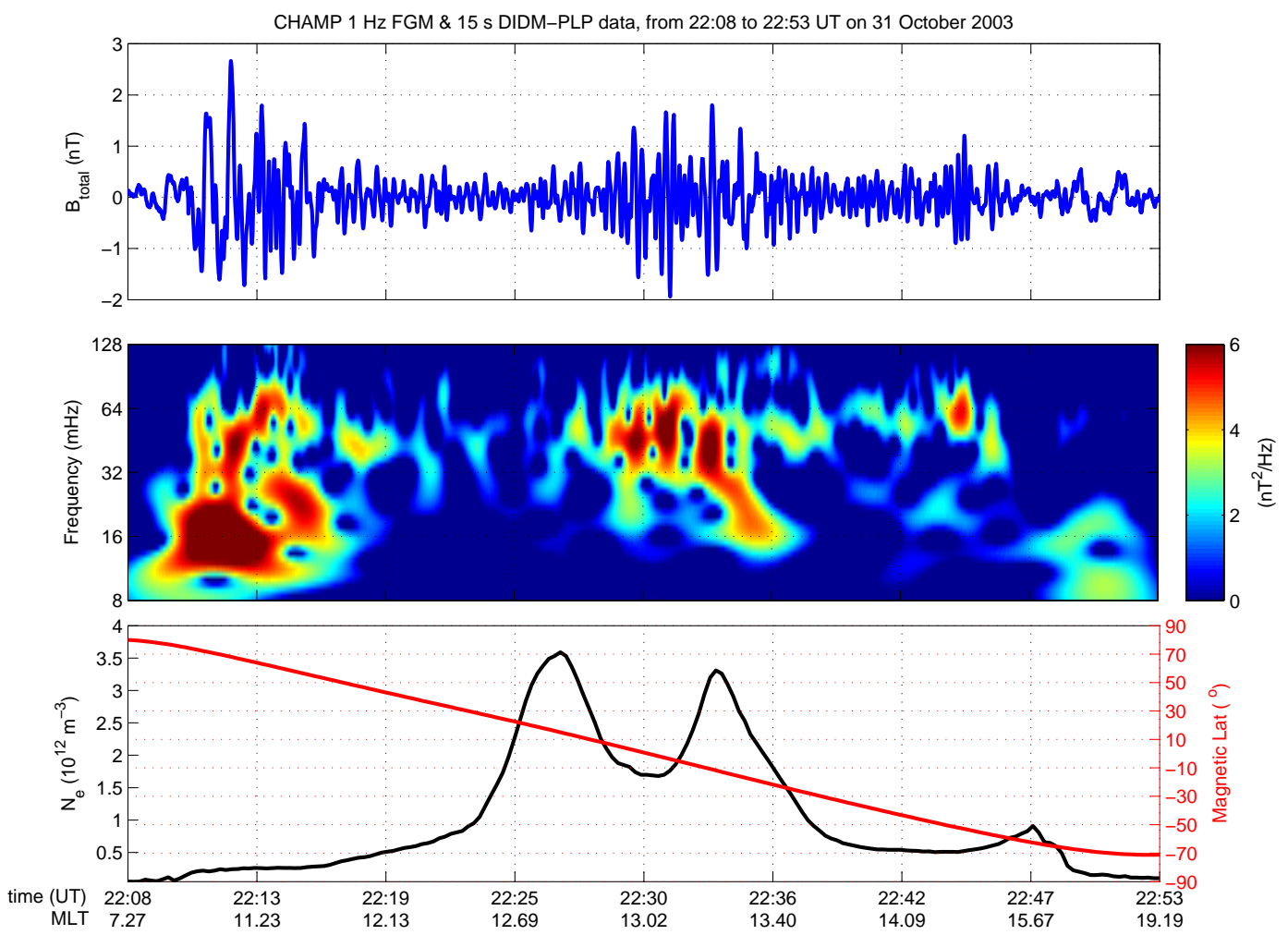

Fig. 5. The CHAMP track from 22:08 to 22:53 UT on 31 October 2003. From top to bottom are shown the time series of the CHAMP total magnetic field, calculated from the $1 \mathrm{~Hz}$ FGM data after applying a $16 \mathrm{mHz}$ high-pass filter, its corresponding wavelet power spectrum as well as the temporal variation of the CHAMP electron density data along with its magnetic latitudinal dependence indicating that the satellite was moving from the north to the south pole. The corresponding MLT values are also given at the bottom of the graph. A prominent Pc3 ULF wave is observed starting at around 22:25 UT and lasting 20 min. The strong ionospheric currents' signatures near the poles covering many frequencies can also be seen in this plot.

orbit with a period of $57 \mathrm{~h}$. For our study, we used magnetic field measurements from the FGM instrument (Balogh et al., 1997) with a time resolution corresponding to one spacecraft spin period, namely $4 \mathrm{~s}$, with a Nyquist frequency of $125 \mathrm{mHz}$. During the Halloween storm the Cluster probes were flying in close configuration, and no significant differences are seen in the ULF wave occurrence between the different probes. Therefore, we only present here the observations from the Cluster-1 satellite.

The Geotail satellite was launched in July 1992 with the aim of studying the structure and dynamics of the Earth's magnetotail over a wide range of distances, extending from the near-Earth region ( $8 R_{\mathrm{E}}$ from the Earth) to the distant tail $\left(\sim 200 R_{\mathrm{E}}\right)$. Since February 1995, when it fulfilled its original objective, Geotail has been placed in an elliptical 9 by $30 R_{\mathrm{E}}$ orbit from where it is providing data on different aspects of the solar wind interaction with the magnetosphere. For this study, we used magnetic field measurements collected by Geotail when the spacecraft traversed from the upstream region of the quasi-perpendicular shock, through the duskside magnetosheath to the nightside outer magnetosphere and the dawnside magnetosheath. The Geotail spacecraft carries fluxgate magnetometers along with a search coil magnetometer, providing magnetic field data in the frequency range below $50 \mathrm{~Hz}$ (Kokubun et al., 1994). The Geotail data used have a time resolution of $3 \mathrm{~s}$, with a Nyquist frequency of $167 \mathrm{mHz}$.

\subsection{ULF wave activity in a LEO orbit}

Figure 3 presents CHAMP total magnetic field time series derived from the $1 \mathrm{~Hz}$ FGM measurements after applying a $16 \mathrm{mHz}$ high-pass filter along with its corresponding wavelet power spectrum in the Pc3 frequency band $(8-128 \mathrm{mHz})$. It was empirically found that a cutoff of $16 \mathrm{mHz}$ for the highpass filter used at the preprocessing of the time series is able to reduce the amplitude of pulsations with frequencies lower than or equal to $10 \mathrm{mHz}$ by approximately $90 \%$. Thus, by this choice, we are certain that all low-varying background activity will be eliminated, as well as any possible contribution by Pc5 ULF waves. Using a higher cutoff would eradicate all influence by Pc4 waves as well, but then Pc3 waves would also suffer its effects, so the selection of $16 \mathrm{mHz}$ was made as a reasonable compromise, in order to leave Pc3 and higher frequency waves as unaffected as possible. The 

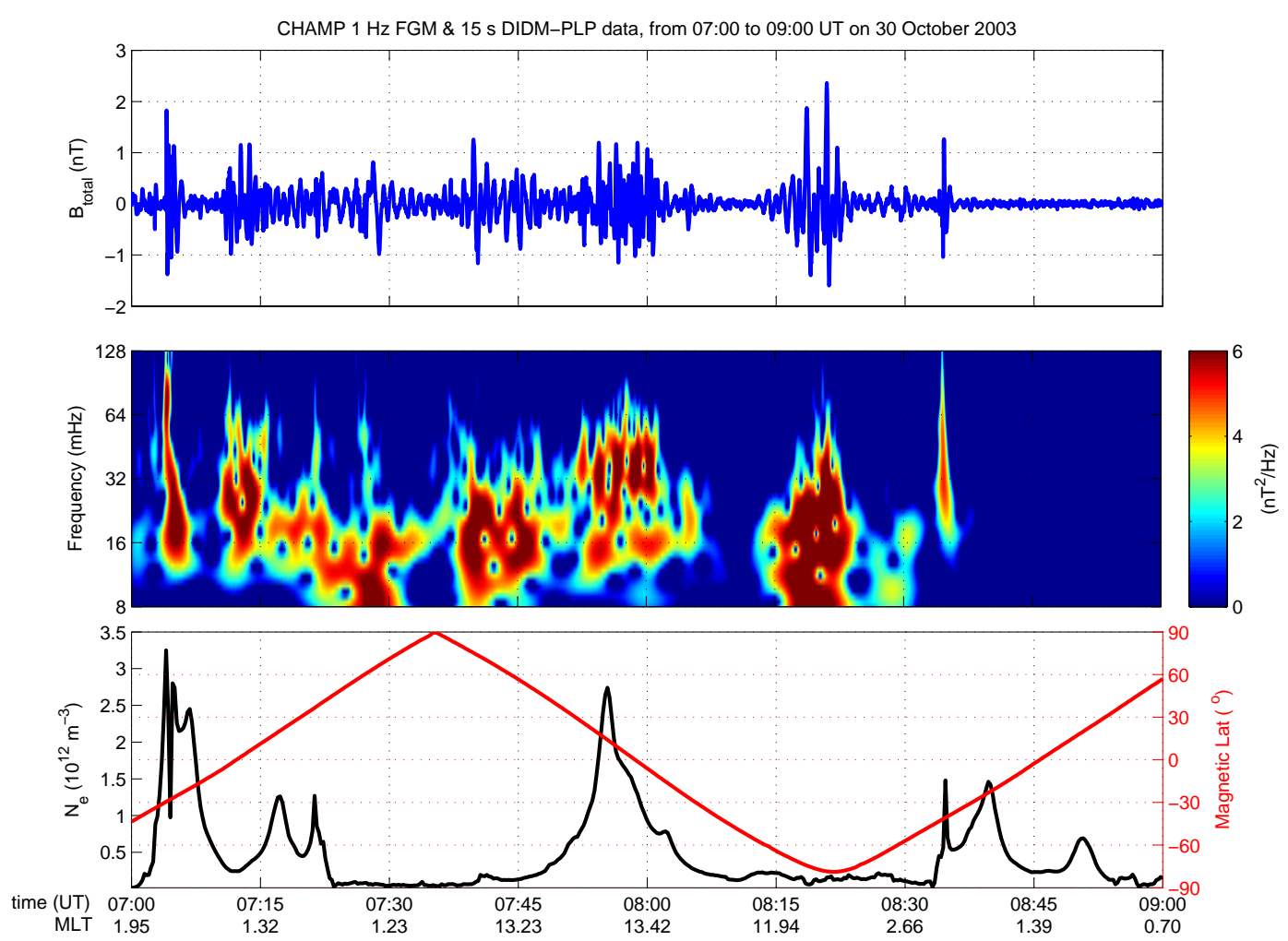

Fig. 6. Event 1: 07:00-09:00 UT, 30 October 2003. As in Fig. 3 but for a longer time period (i.e., two hours instead of the $\sim 45$ min duration of the LEO track).

selection of the cutoff for the Pc5 case in Sects. 3.2-3.4 was based on similar criteria.

Corresponding to the time interval from 07:35 to 08:21 UT on 30 October 2003, which according to the plot of Fig. 1, refers to the middle part of the short recovery phase of the magnetic superstorm, characterized by the first minimum of Dst index (i.e., $-353 \mathrm{nT}$ ), it also includes electron density data derived from the $15 \mathrm{~s}$ Planar Langmuir Probe (PLP) measurements. The inclusion of the electron density recordings helps to identify time segments of the signal that contain signatures of post-sunset equatorial spread $\mathrm{F}$ (ESF) events (Stolle et al., 2006), and therefore, discriminate between Pc3 wave and plasma depletion occurrence. The corresponding values of the CHAMP magnetic latitude (shown in red) and magnetic LT (MLT) are also provided in the graph. Figures 4 and 5 show similar graphs to Fig. 3 but from 14:26 to 15:15 UT and between 22:08 and 22:53 UT, respectively, both on 31 October 2003.

It is worth noting that Pc3 waves are observed over the auroral zones and the dayside equator, while wave power decreases significantly at mid-latitudes, a profile that we attribute to strong ionospheric currents (see also Fig. 6). Furthermore, a dramatic north to south asymmetry in the Pc3 waves was observed over the auroral zones. On the other hand, because the equatorial electrojet disappears on the nightside, Pc3 wave power has significantly decreased over the nightside equator. Wave activity that is sporadically observed in the nightside is likely due to phenomena like currents enhanced during substorms or the propagation of $\mathrm{Pi} 2$ waves from the magnetotail.

In Fig. 1, the three time intervals in which Pc3 ULF wave activity was initially identified in CHAMP observations on the morning of 30 October 2003 and in the afternoon and evening of 31 October 2003, which are selected and further expanded into two-hour intervals for analysis using Cluster and Geotail measurements, are marked in red. Moreover, the locations of Cluster-1 and Geotail satellites during these three time intervals are highlighted in Fig. 2.

\subsection{Event 1: 07:00-09:00 UT on 30 October 2003}

Centered around the first Pc3 wave event identified in the CHAMP $1 \mathrm{~Hz}$ FGM measurements, Fig. 6 presents the total magnetic field time series along with its corresponding wavelet power spectrum in the Pc3 band $(8-128 \mathrm{mHz})$ from 07:00 to 09:00 UT on 30 October 2003. Electron density recordings collected by the PLP instrument are also shown during this interval in the recovery phase of the first magnetic superstorm studied. LEO satellites such as CHAMP traversing the topside ionosphere are usually considered to be able to adequately observe waves only in higher ULF frequencies (see also Sect. 3 above). 

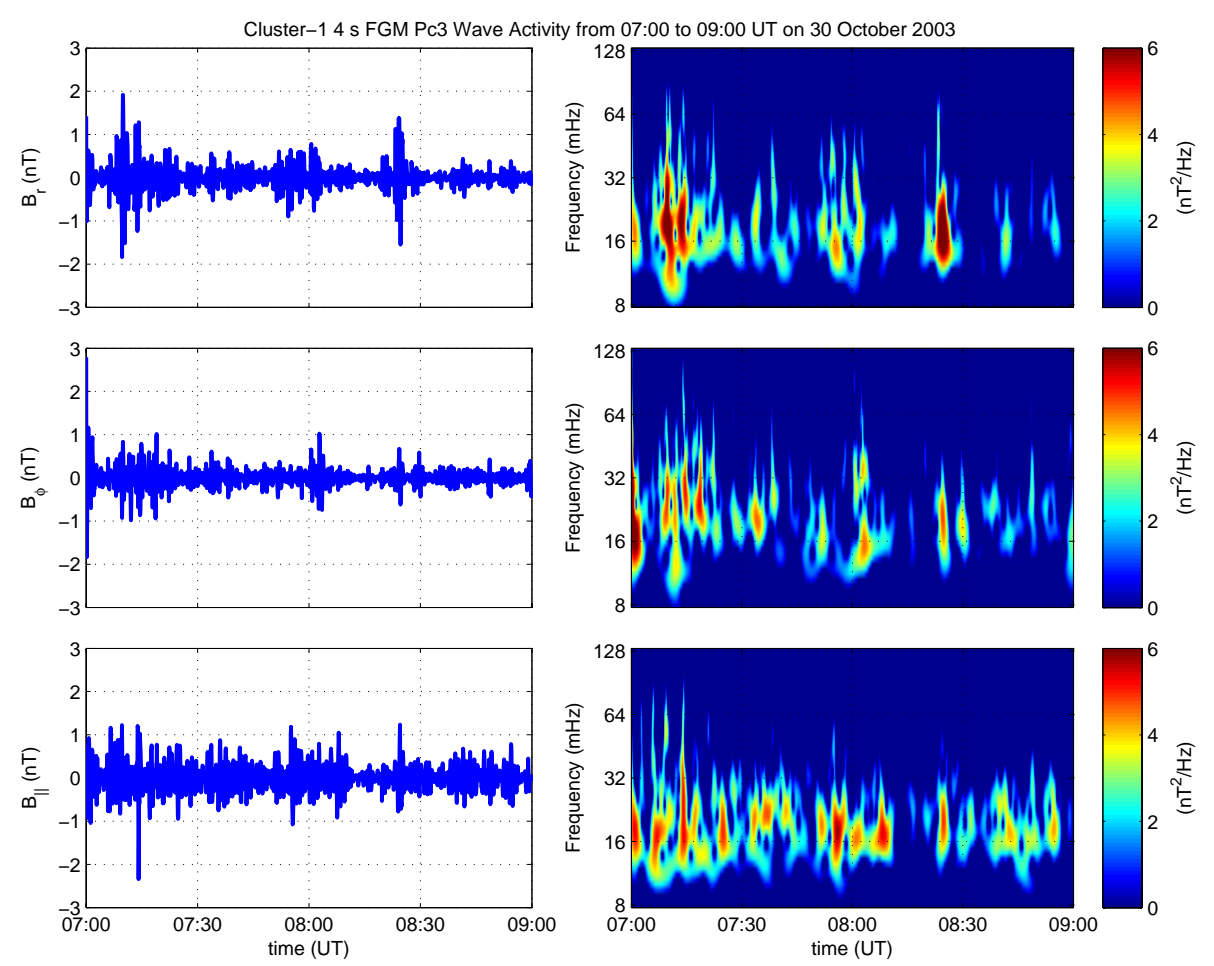

Fig. 7. Event 1: 07:00-09:00 UT, 30 October 2003. The Cluster-1 Pc3 (8-128 mHz) activity. Left column: From top to bottom are shown the time series of the poloidal, toroidal and compressional components, respectively, of the magnetic field, calculating from the $4 \mathrm{~s}$ FGM data after applying a $16 \mathrm{mHz}$ high-pass filter. Right column: From top to bottom are shown the corresponding wavelet power spectra.

On the other hand, the Cluster-1 poloidal, toroidal and compressional magnetic field time series, derived from the $4 \mathrm{~s}$ FGM measurements, after applying a $16 \mathrm{mHz}$ and a $2 \mathrm{mHz}$ high-pass filter, are shown in Figs. 7 and 8 along with their corresponding wavelet power spectra in the Pc3 and Pc5 (1-32 mHz) frequency band. The ULF oscillations, clearly visible on the quiet background, are similar on all four satellites of the Cluster mission and therefore provide an indication of the scale-size of the waves, which is related to the satellites' distances of separation. The MFA components of the magnetic field time series are, however, shown only for the Cluster-1 satellite.

In Figs. 9 and 10, the poloidal, toroidal and compressional magnetic field time series, derived from the $3 \mathrm{~s}$ FGM measurements of Geotail, after applying a $16 \mathrm{mHz}$ and a $2 \mathrm{mHz}$ high-pass filter, are shown along with their corresponding wavelet power spectra in the Pc3 and Pc5 frequency band. It is worth noting that Sakurai and Tonegawa (2005) have identified large amplitude Pc3 waves in the magnetic and electric field measurements collected by Geotail on the morning of 30 October 2003. Specifically, they found Pc3 waves at 07:20-07:40 UT and 07:40-07:55 UT on 30 October 2003.

During the recovery phase of the first peak of magnetic superstorm, the Geotail satellite traversed through the dusk-side magnetosheath towards the outer magnetosphere (Fig. 2). In the heart of the magnetosheath, there are no no- ticeable oscillations in the three components of the magnetic field, but appear only as the satellite approaches the magnetopause. In light of this, the Pc5 observations made both by the Geotail satellite as well as the Cluster-1 satellite well within the magnetosphere are attributed to shock waves compressing the Earth's magnetosphere (pressure pulse excitation mechanism of ULF waves as discussed in the Introduction). Associated with the interplanetary coronal mass ejection (ICME) that was observed on 29 October 2003, the shock speed estimated from the travel time from the Sun to the Earth exceeded $2000 \mathrm{~km} \mathrm{~s}^{-1}$.

Visible to the naked eye is the changing distance in time between the peaks of the waves, indicating the frequency is changing with the radial distance from the Earth. We will return to this in the subsequent sections on ULF waves observed as the second stronger peak $(-383 \mathrm{nT})$ of the magnetic superstorm that was in progress.

\subsection{Event 2: 14:00-16:00 UT on 31 October 2003}

With the simultaneous observations from the CHAMP, Cluster-1 and Geotail satellites, we studied long-lasting Pc3 and Pc5 waves in the recovery phase of the second peak of the magnetic superstorm when the Dst index had a value below -80 nT. From 14:00 to 16:00 UT on 31 October 2003, the Cluster-1 satellite flew in the dawnside Northern Hemisphere of the magnetosphere, while the Geotail satellite was 

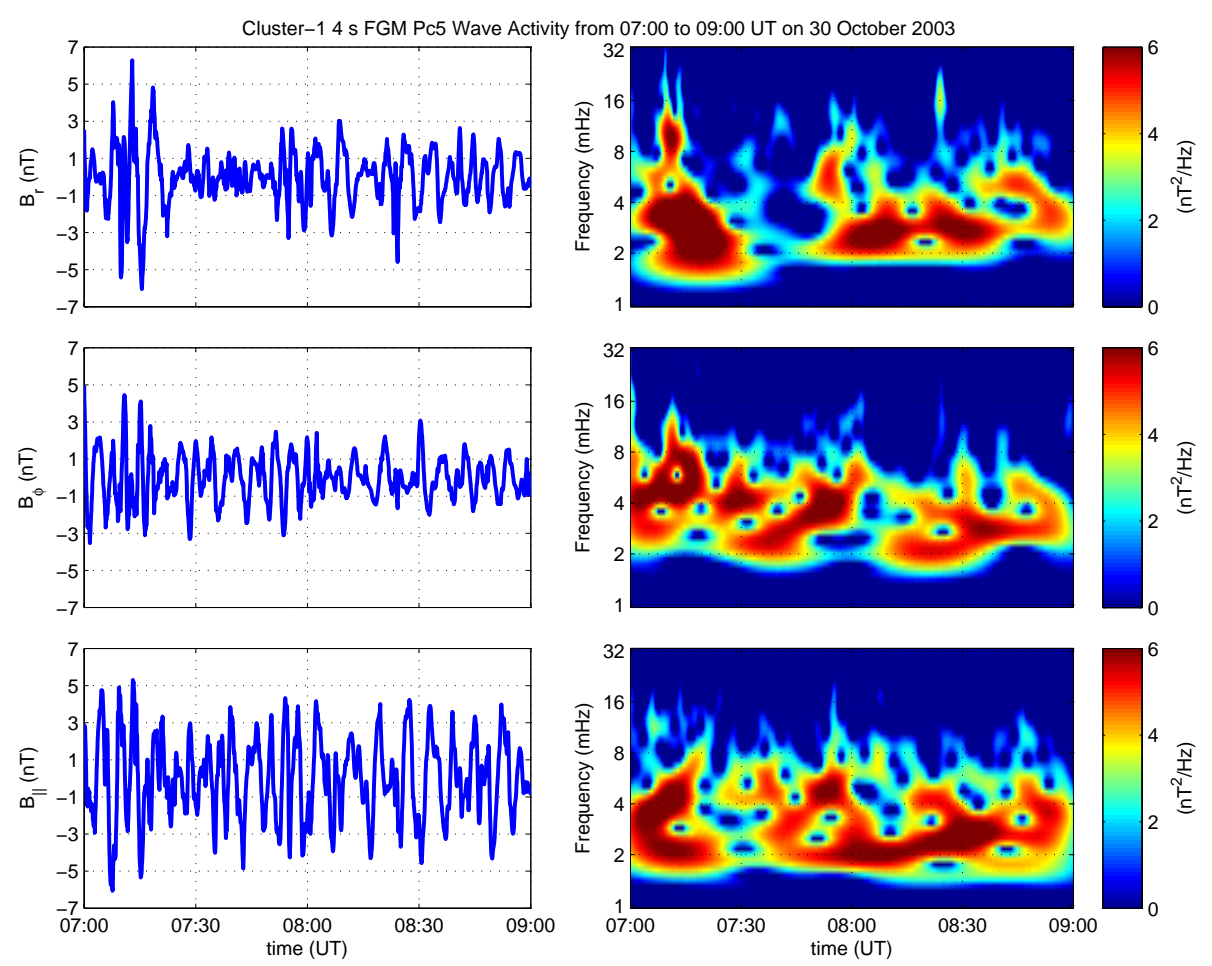

Fig. 8. Event 1: 07:00-09:00 UT, 30 October 2003. The Cluster-1 Pc5 (1-32 mHz) activity. Left column: From top to bottom are shown the time series of the poloidal, toroidal and compressional components, respectively, of the magnetic field, calculating from the $4 \mathrm{~s}$ FGM data after applying a $2 \mathrm{mHz}$ high-pass filter. Right column: From top to bottom are shown the corresponding wavelet power spectra.

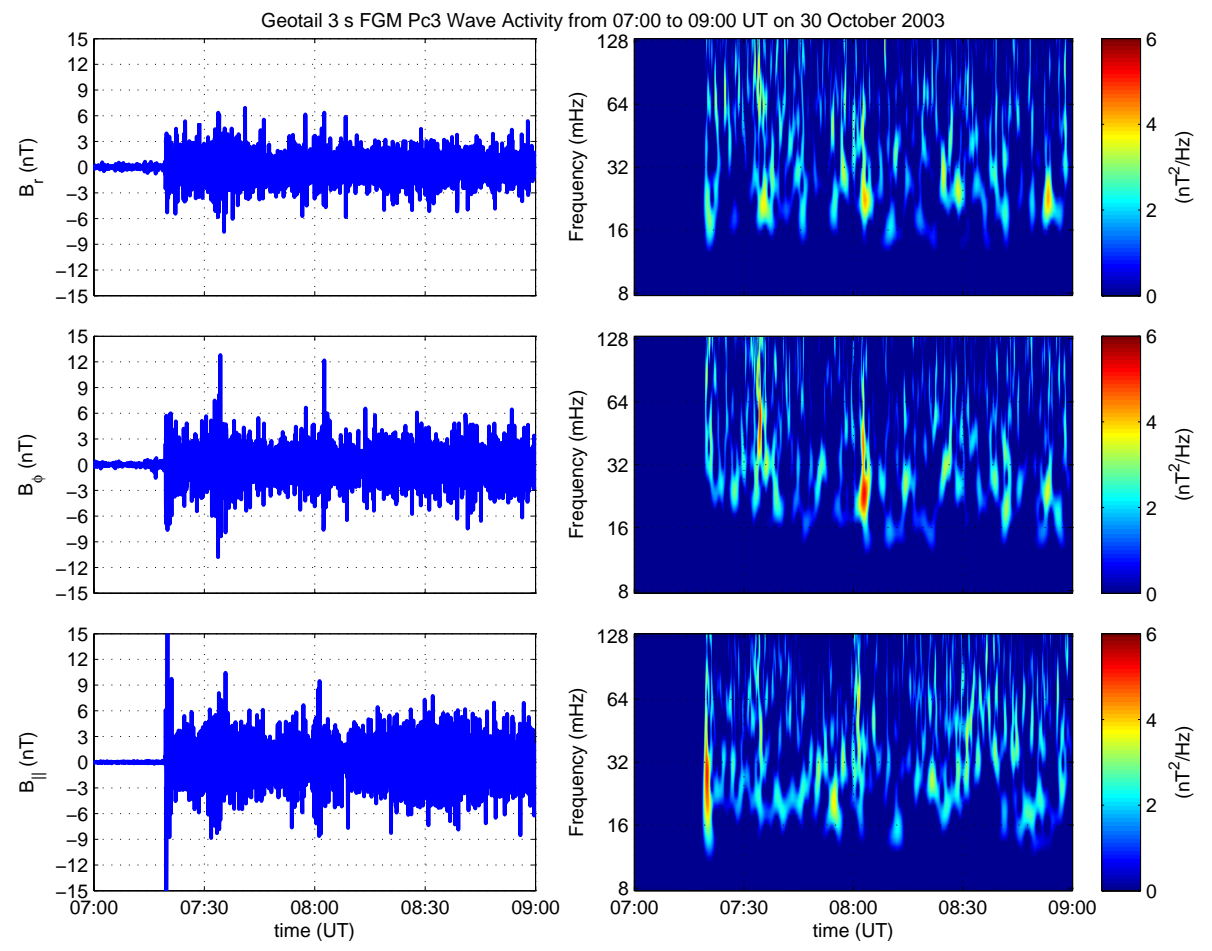

Fig. 9. Event 1: 07:00-09:00 UT, 30 October 2003. As in Fig. 7 but for the Geotail Pc3 activity. 


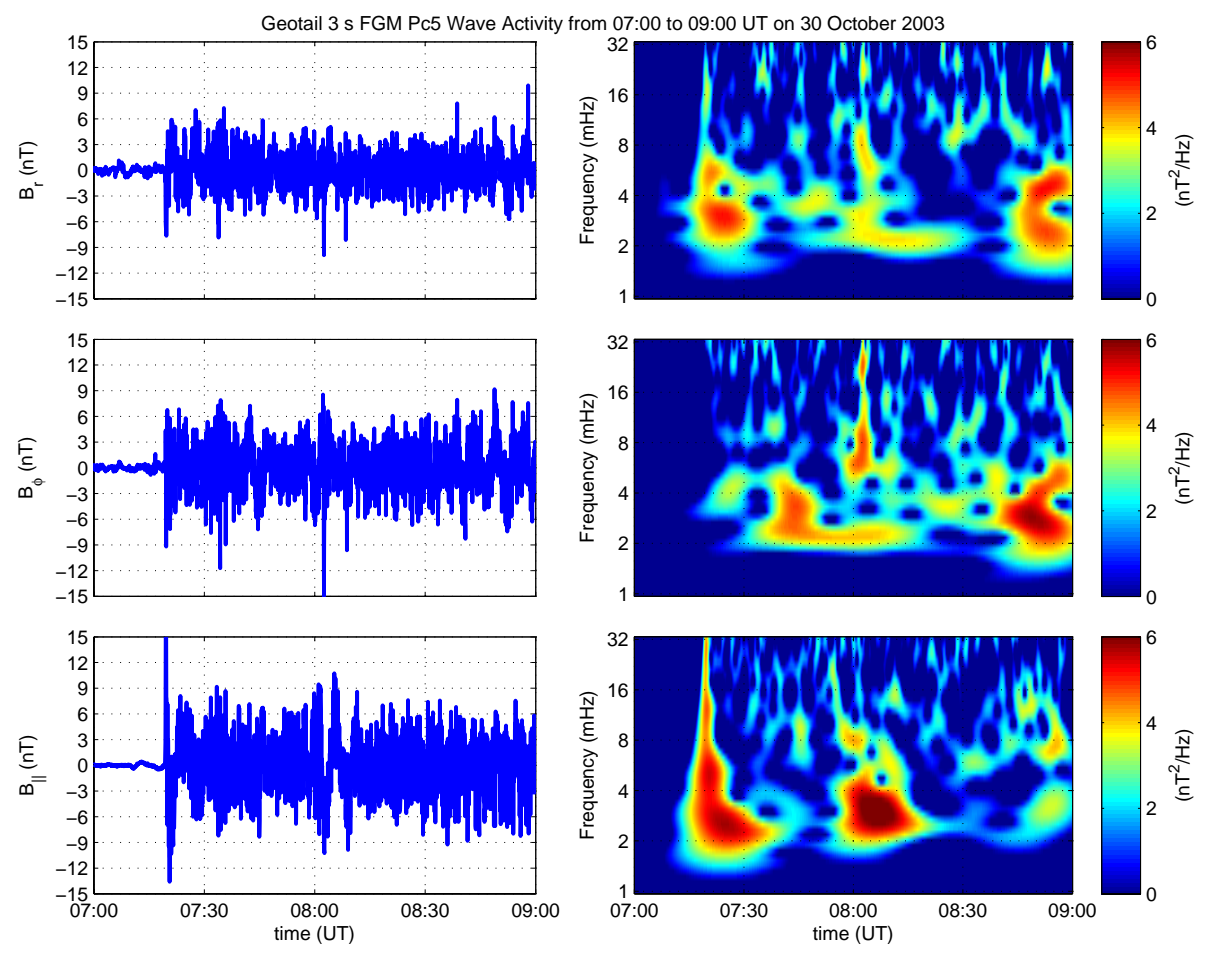

Fig. 10. Event 1: 07:00-09:00 UT, 30 October 2003. As in Fig. 8 but for the Geotail Pc5 activity.

in the duskside of the magnetosheath, providing us with a unique opportunity to study also the ULF waves' global distribution (Fig. 2).

Figures 11 and 12 show the wavelet power spectra of FGM measurements from the CHAMP, Cluster- 1 and Geotail satellite covering the Pc3 and Pc5 frequency bands, respectively. Specifically, the upper panel corresponds to the continuous wavelet power spectra of the CHAMP total magnetic field measurements, followed by the wavelet analysis results of each MFA magnetic field component observed by the Cluster-1 and Geotail satellites. From top to bottom, the radial magnetic field $B_{\mathrm{r}}$, azimuthal magnetic field $B_{\varphi}$ and parallel magnetic field $B_{\|}$are, however, not consistent.

In the period from 14:24 UT to 15:24 UT, among the MFA components of Cluster-1 magnetic field time series, the radial component had the largest amplitude, the azimuthal component was smaller, and the parallel component was the weakest. As we can see in Fig. 11, from the radial to the parallel component, the wavelet power spectrum density in the Pc3 frequency band decreased from $6 \mathrm{nT}^{2} \mathrm{~Hz}^{-1}$ to approximately $4 \mathrm{nT}^{2} \mathrm{~Hz}^{-1}$. The frequency range covered by the wavelet power enhancement in the three MFA magnetic field components was among $16-60 \mathrm{mHz}$, with the spectrum peak frequency near $34 \mathrm{mHz}$.

The amplitude of the wavelet power enhancement observed by the Cluster- 1 and Geotail satellites in the Pc5 frequency band also varied; the MFA magnetic field component with the largest amplitude observed by both Cluster-
1 and Geotail was the parallel. From the radial to the parallel component, the wavelet power spectrum density decreased from approximately $4.2 \mathrm{nT}^{2} \mathrm{~Hz}^{-1}$ to $6 \mathrm{nT}^{2} \mathrm{~Hz}^{-1}$. The wavelet power enhancement in the three MFA magnetic field components seen in Fig. 12 was between $2-4 \mathrm{mHz}$, with the spectrum peak frequency near $2.8 \mathrm{mHz}$.

From these observations, we can conclude that Pc3 and Pc5 waves can simultaneously occurred and be observed over a large portion of the magnetosphere, from the outer limits to the topside ionosphere and from morning to evening with a similar spectral frequency. Nonetheless, in the time interval before 14:36 UT neither Pc3 nor Pc5 waves are observed by the Geotail satellite. In the magnetosheath where the Geotail satellite was located, ULF waves are common and an important source for Pc3 -5 waves observed in the magnetosphere. Although ULF waves have an important role to play in the solar wind-magnetosphere energy coupling, inhomogeneity due to the stress of the increased solar wind dynamic pressure exerted on the magnetopause seems to have a crucial effect on the generation or propagation of ULF waves (i.e., Blanco-Cano et al., 2006, and references therein).

\subsection{Event 3: 21:00-23:00 UT on 31 October 2003}

ULF waves were observed throughout the recovery phase of the magnetic superstorm on 31 October 2003. In Figs. 13 and 14, we focus on the interval between 21:00 UT and 23:00 UT, where the wavelet power spectra of FGM measurements from the CHAMP, Cluster-1 and Geotail satellites 


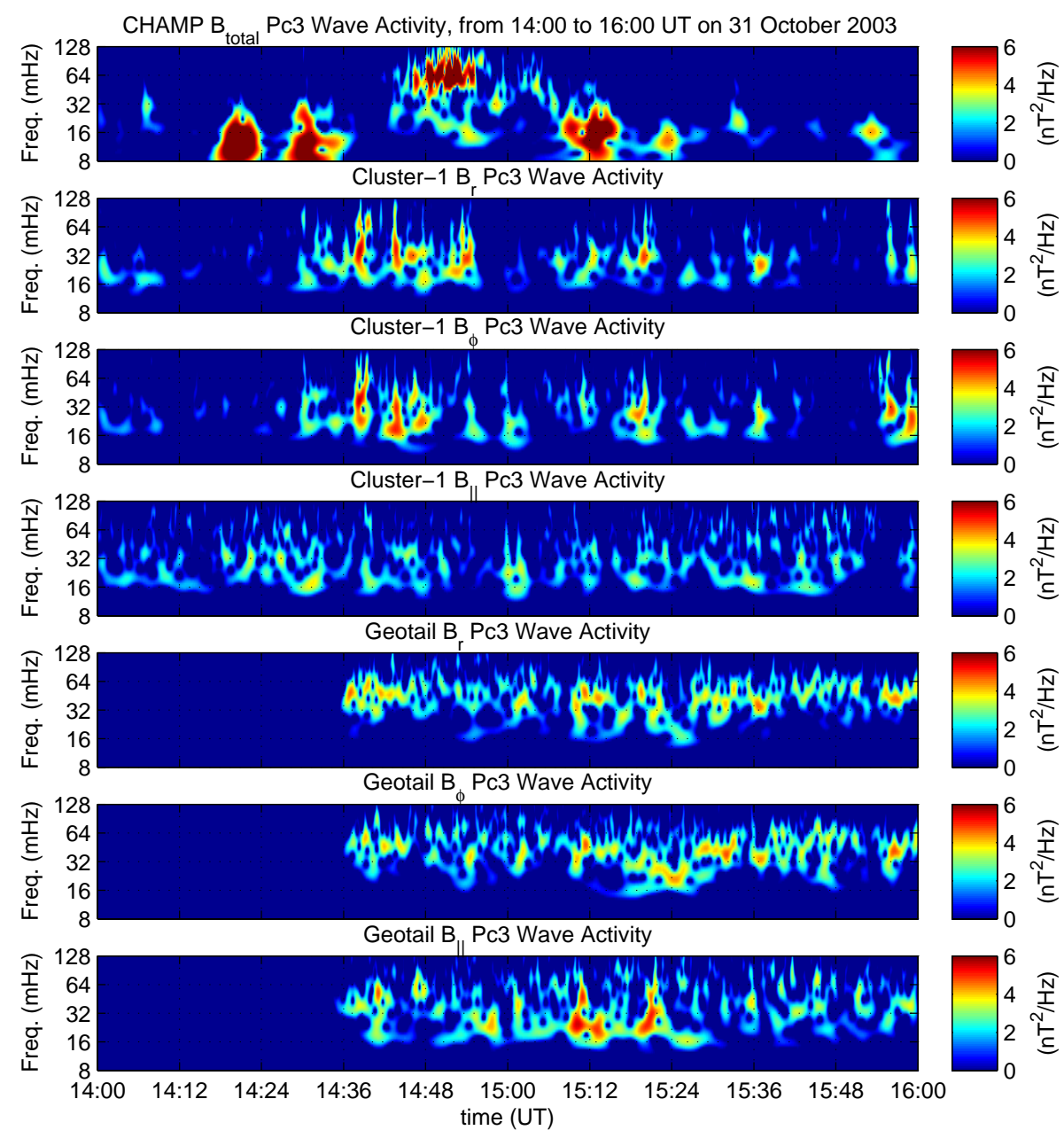

Fig. 11. Event 2: 14:00-16:00 UT, 31 October 2003. From top to bottom are shown the wavelet power spectra of the Pc3 ULF wave activity from CHAMP total magnetic field, Cluster-1 poloidal, toroidal and compressional components as well as Geotail MFA components.

is separated in the Pc3 and Pc5 frequency band. Similarly to Sect. 3.3, the upper panel corresponds to the continuous wavelet power spectra of the CHAMP total magnetic field measurements, followed by the wavelet analysis results of each MFA magnetic field component observed by the Cluster-1 and Geotail satellites. From top to bottom, the radial magnetic field $B_{\mathrm{r}}$, azimuthal magnetic field $B_{\varphi}$ and parallel magnetic field $B_{\|}$are, however, not consistent.

Pc3 waves are observed throughout the trajectory of the CHAMP, Cluster-1 and Geotail satellites, but more pronounced along the LEO of the CHAMP satellite between 22:00 and 22:30 UT and in the parallel MFA component of the magnetic field as this was measured by Geotail. The peak wavelet power spectrum density reaches a value of approximately $6 \mathrm{nT}^{2} \mathrm{~Hz}^{-1}$. The three satellites observations are different in terms of amplitude as well as frequency. The Pc3 waves observed by Cluster-1 between 21:00 and 21:30 UT are mainly in the lower frequency part of the spectra, while the high-frequency waves observed by Geotail are not visi- ble. The Pc3 waves frequency range is observed between 32 and $64 \mathrm{mHz}$.

The frequency of ULF waves is not affected only by the geometry of the magnetic field and boundaries such as the magnetopause and the plasmapause, but also by the generation mechanism. It varies with L-shell value and local time. During the time interval between 21:00 and 23:00 UT, the Geotail satellite traversed through the dawnside magnetosheath towards the interplanetary medium, while the Cluster-1 satellite was flying within the magnetosphere crossing L shell 11.7 to 5.3. Based on observations from the Cluster-1 satellite, along with the GOES-10 and 12, as well as the Polar satellites, Wang et al. (2008) have shown that ULF oscillations' period varied with Cluster-1 observing the shortest period and Polar the longest. The period of toroidal and poloidal mode ranged from 128 to $512 \mathrm{~s}$, with the spectrum peak period near $256 \mathrm{~s}$ indicative of a Pc5 wave activity.

As we can see in Fig. 14, from the radial to the parallel component, the wavelet power spectrum density in the Pc5 


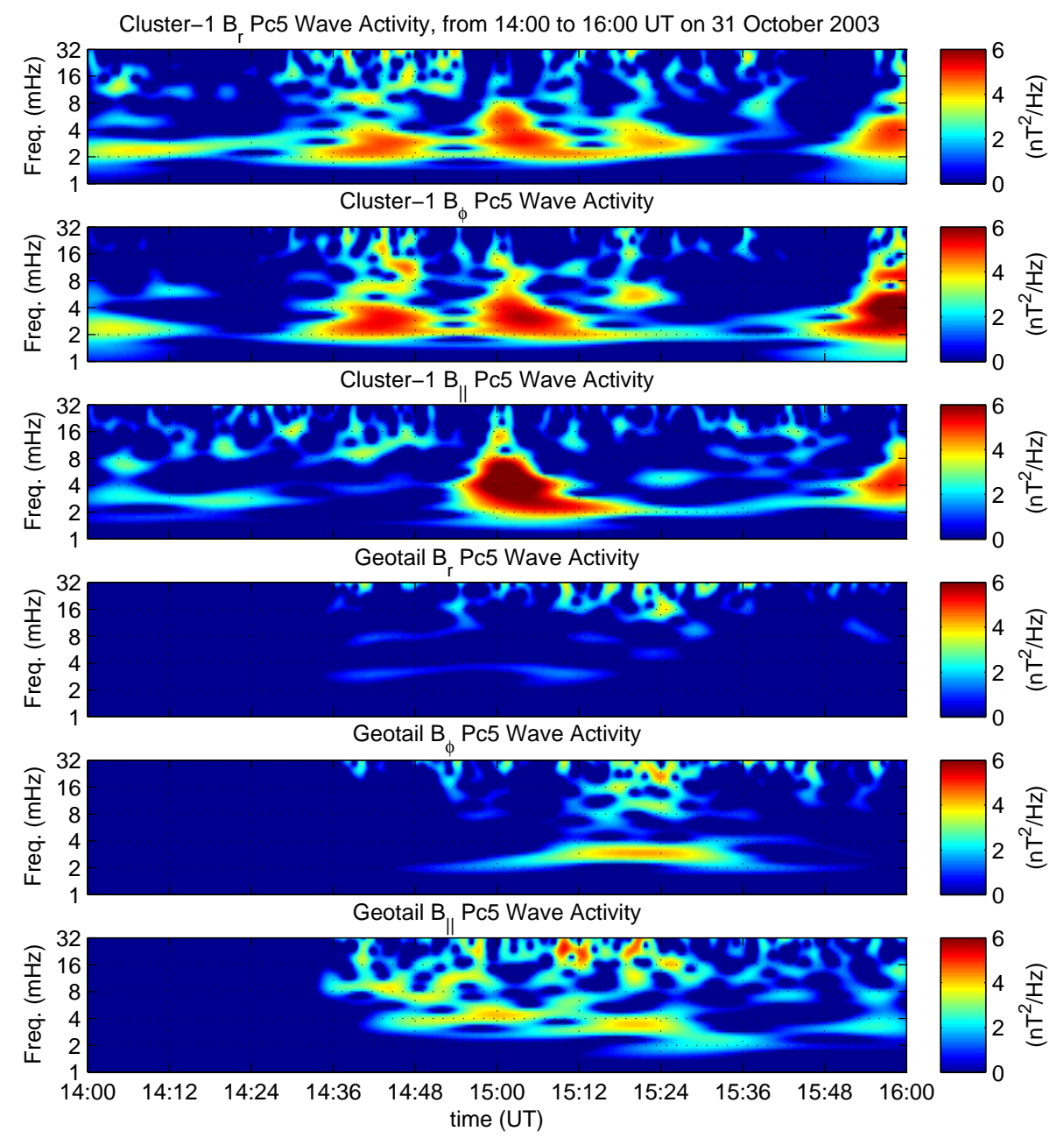

Fig. 12. Event 2: 14:00-16:00 UT, 31 October 2003. From top to bottom are shown the wavelet power spectra of the Pc5 ULF wave activity from Cluster-1 poloidal, toroidal and compressional components as well as Geotail MFA components.

frequency band decreased remarkably from $6 \mathrm{nT}^{2} \mathrm{~Hz}^{-1}$ to approximately $2 \mathrm{nT}^{2} \mathrm{~Hz}^{-1}$ in the MFA components of the Geotail magnetic field time series. In the toroidal component of the magnetic field, the Pc5 oscillations had the largest amplitude, while the poloidal components were weaker, and the compressional component almost could not be seen compared to the above two modes.

\section{Discussion and conclusions}

We have analyzed multi-point observations from the CHAMP, Cluster and Geotail missions during the Halloween 2003 superstorm in order to investigate ULF wave activity present during the evolution of the the storm with newly developed tools based on continuous wavelet transforms. As demonstrated in the previous sections, these wavelet-based tools are capable of examining magnetic field measurements from:
- a topside ionosphere or a magnetospheric mission;

- a single-satellite or a multi-satellite mission;

and consequently, identify ULF waves at the:

- Pc3 (topside ionosphere and magnetospheric missions) or

- Pc4-5 (magnetospheric missions) frequency range.

We have started our analysis by examining CHAMP data for signatures related to ULF waves occurring during different phases of the magnetic superstorm. Due to the CHAMP satellite's fast motion through field lines in a LEO orbit, we have been able to reliably detect Pc3 (but not Pc4-5) waves along its orbit. Subsequently, we have selected three prominent Pc3 wave events as seen in CHAMP magnetic field measurements in the morning of 30 October 2003 and in the afternoon and night of 31 October 2003 for further analysis. With the use of Cluster-1 and Geotail data, we were able to 


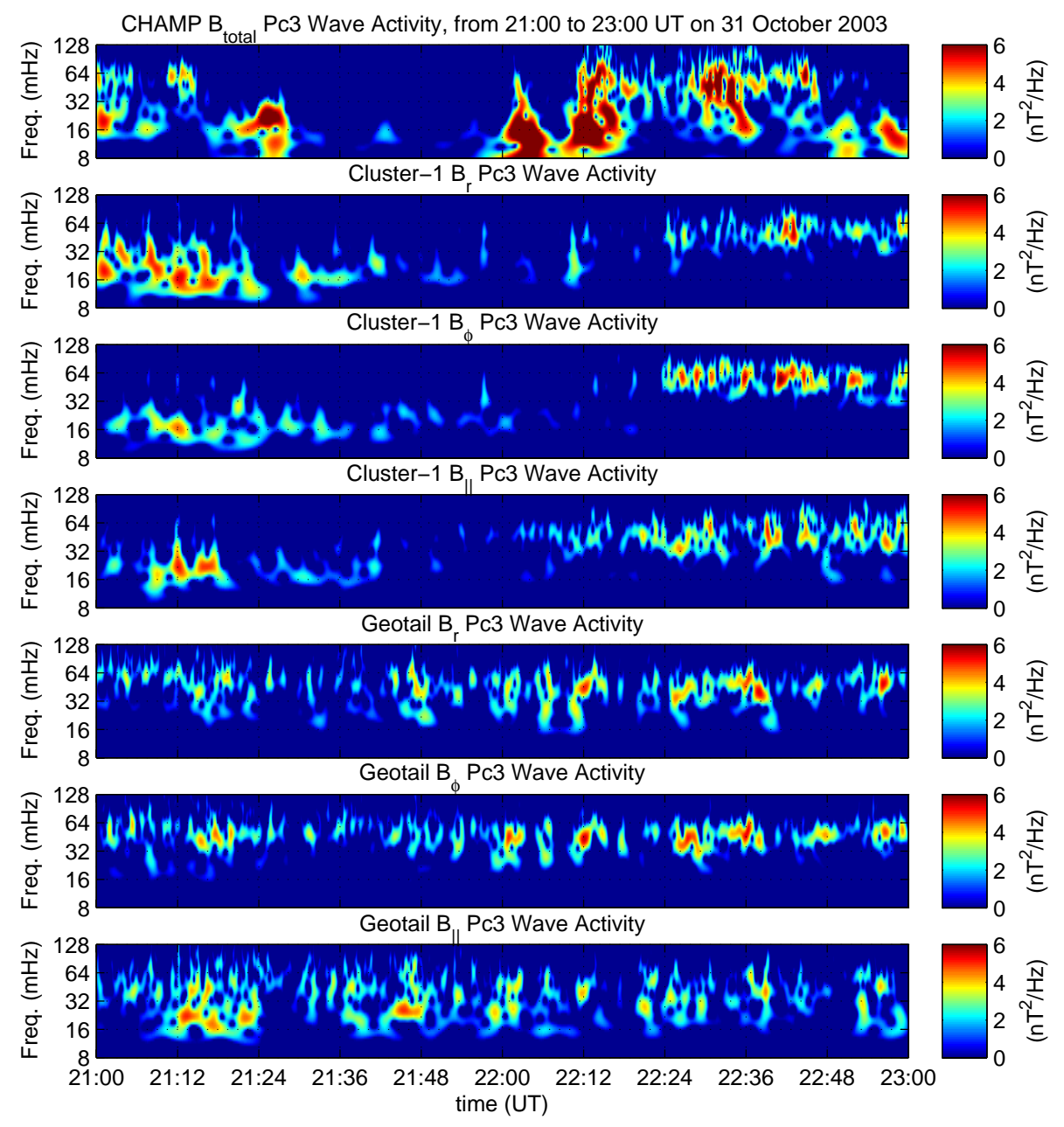

Fig. 13. Event 3: 21:00-23:00 UT, 31 October 2003. As in Fig. 11.

present clear evidence of Pc3 wave activity observed simultaneously by satellites in the topside ionosphere to the outer magnetosphere and the magnetosheath. Moreover, based on Cluster-1 and Geotail data, we were able to draw inferences on Pc5 wave activity associated with the specific superstorm.

During the Halloween 2003 superstorm, strong compression of the magnetotail, as evidenced by enhanced tail field strengths and increased plasma density, was observed by Geotail (Miyashita et al., 2005). Sakurai and Tonegawa (2005) have identified large amplitude Pc3 waves in the magnetic and electric field measurements collected by Geotail at 01:00-01:30, 07:20-07:40, 07:40-07:55 and 08:1008:40 UT on 30 October 2003. Our study provides evidence for Pc3 wave activity detected by Geotail satellite between 07:00 and 09:00 UT on 30 October 2003, covering the second, third and fourth time intervals analyzed by Sakurai and Tonegawa.

These are past studies on the Halloween 2003 superstorm that are consistent with the results presented in this paper for the third time interval, i.e., from 21:00 to $23: 00$ on 31 Oc- tober 2003. Zong et al. (2007) examined Cluster mission magnetic field data collected between 21:30-22:30 UT on 31 October 2003 and found evidence for Pc5 waves occurrence. The observed magnetic ULF pulsations were dominated by the toroidal mode, accompanied by a relatively weak poloidal mode. The ULF modulation terminated where higher frequency fluctuations appeared as the Cluster spacecraft entered the plasmasphere boundary layer (PBL), where the plasma ion density was abruptly elevated. In addition, Wang et al. (2008) identified Pc5 wave activity between 21:00-23:00 UT on 31 October 2003 in Cluster-1, GOES 10, GOES 12 and Polar magnetic field measurements. In comparison to the observations of Wang et al. (2008), we have found that Pc5 waves can be seen in all the MFA components of the Cluster-1 spacecraft during the same time interval.

Nonetheless, the analysis presented in the previous sections encompasses a total of three consecutive, though distinct time intervals of enhanced ULF wave activity with simultaneous observations spanning from the magnetotail to the innermost magnetosphere. 


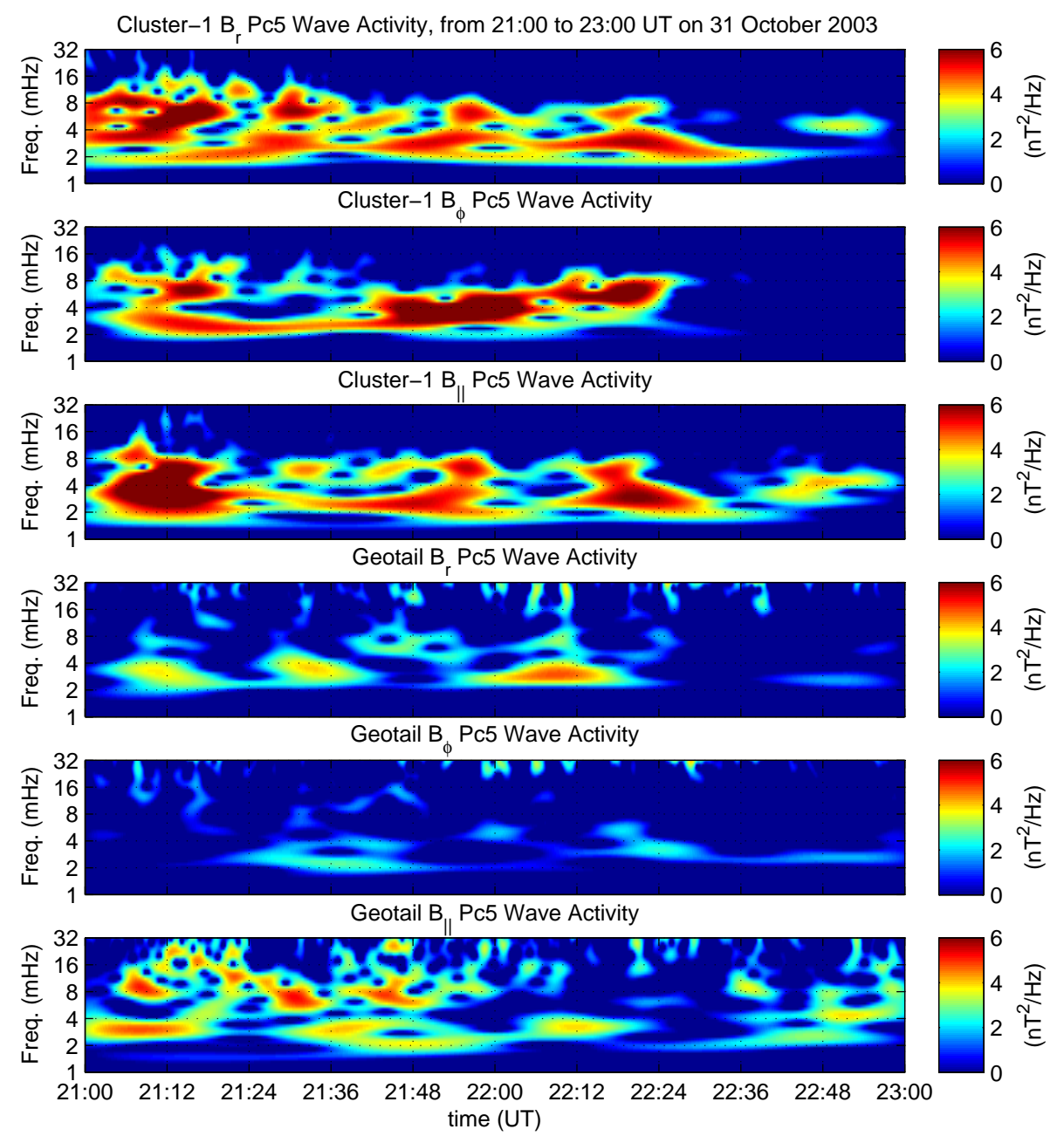

Fig. 14. Event 3: 21:00-23:00 UT, 31 October 2003. As in Fig. 12.

On the other hand, Engebretson et al. (2007) have reported unusual wave activity in the Pc1-2 frequency range observed by the Cluster spacecraft in association with the Halloween 2003 storm. At the onset of the superstorm on 29 October 2003, intense broadband activity in the frequency range between $\sim 0.1$ and $0.6 \mathrm{~Hz}$ appeared simultaneously at all four spacecraft located on both sides of the magnetic equator at perigee (near 14:00 UT and 08:45 MLT). It should be noted that wave power was especially strong and more structured in frequency in the compressional component, while a minimum was observed at $0.38 \mathrm{~Hz}$, corresponding to the oxygen ion cyclotron frequency.

Apart from Wang et al. (2008), Pc5 waves on 31 October 2003 identified in the geosynchronous GOES satellites' measurements, Pilipenko et al. (2010) have found that during periods of ground Pc5 activity enhancement on 29 and 31 October 2003 (05:00-24:00 and 00:00-19:00 UT, respectively), the GOES 10 satellite located in the morning sector of the magnetosphere detected Pc5 pulsations, most evident in the toroidal component.
Rae et al. (2005) presented an interval of extremely longlasting narrowband Pc5 pulsations during the recovery phase of a large geomagnetic storm on 25 November 2001. These pulsations occurred continuously for many hours and were observed throughout the magnetosphere and in the dusksector ionosphere. The fortuitous spacecraft conjunction of the Cluster, Polar, and geosynchronous satellites in the dusk sector during a $3 \mathrm{~h}$ subset of this interval has allowed extensive analysis of the global nature of the pulsations and the tracing of their energy transfer from the solar wind to the ground. Herein, we demonstrate the applicability of our tools to the analysis of similar spacecraft conjunctions.

The consistency between the Pc3 and Pc5 wave observations confirm the applicability and the potential of our wavelet-based algorithms for the analysis of multiinstrument multi-satellite observations and the detection, identification and classification of ULF waves. In the past decade, a critical mass of high-quality scientific data on the electric and magnetic fields in the Earth's magnetosphere has been progressively collected. This data pool will be further 
enriched by the measurements of the upcoming ESA/Swarm mission, a constellation of three satellites in three different polar orbits between 400 and $550 \mathrm{~km}$ altitude, which will be launched in 2013. This data pool provides unique opportunities to study ULF pulsations in the magnetosphere (e.g., Constantinescu et al., 2007; Usanova et al., 2008; Sarris et al., 2009; Picket et al., 2010). New analysis tools that can cope with increased volume of measurements by numerous spacecraft located at different regions of the magnetosphere, similar to the ones employed in the present study, will effectively enhance the scientific exploitation of the continuously accumulated data.

Acknowledgements. This work has received funding from the European Space Agency under contract ESTEC 4000103770/11/NL/JA/ef and from the European Community's Seventh Framework Programme under grant agreement no. 284520. We gratefully acknowledge ESA's Cluster Active Archive, DARTS at the Institute of Space and Astronautical Science, JAXA in Japan, and Helmholtz Centre Potsdam GFZ, German Research Centre for Geosciences, for supplying data used in this study.

Guest Editor A. Masson thanks C. Watt and four anonymous referees for their help in evaluating this paper.

\section{References}

Alexandrescu, M., Gibert, D., Hulot, G., Le Mouel, J.-L., and Saracco, G.: Worldwide wavelet analysis of geomagnetic jerks, J. Geophys. Res., 101, 21975-21994, doi:10.1029/96JB01648, 1996.

Anderson, B. J., Engebretson, M. J., Rounds, S. P., Zanetti, L. J., and Potemra, T. A.: A statistical study of Pc3-5 pulsations observed by the AMPTE/CCE magnetic fields experiment 1, Occurrence distributions, J. Geophys. Res., 95, 10495-10523, doi:10.1029/JA095iA07p10495, 1990.

Anderson, B. J., Erlandson, R. E., and Zanetti, L. J.: A statistical study of Pc 1-2 magnetic pulsations in the equatorial magnetosphere: 2. Wave properties, J. Geophys. Res., 97, 3089-3101, doi:10.1029/91JA02697, 1992.

Baddeley, L. J., Yeoman, T. K., Wright, D. M., Davies, J. A., Trattner, K. J., and Roeder, J. L.: Morning sector driftbounce resonance driven ULF waves observed in artificiallyinduced HF radar backscatter, Ann. Geophys., 20, 1487-1498, doi:10.5194/angeo-20-1487-2002, 2002.

Baker, D. N. and Daglis, I. A.: Radiation belts and ring current, in: Space Weather - Physics and Effects, edited by: Bothmer, V. and Daglis, I. A., pp. 173-202, Springer Verlag, Berlin, 2007.

Baker, D. N., Kanekal, S. G., Li, X., Monk, S. P., Goldstein, J., and Burch, J. L.: An extreme distortion of the Van Allen belt arising from the 'Halloween' solar storm in 2003, Nature, 432, 878-881, doi:10.1038/nature03116, 2004.

Balasis, G. and Mandea, M.: Can electromagnetic disturbances related to the recent great earthquakes be detected by satellite magnetometers?, special issue "Mechanical and Electromagnetic Phenomena Accompanying Preseismic Deformation: from Laboratory to Geophysical Scale", edited by: Eftax- ias, K., Chelidze, T., and Sgrigna, V., Tectonophysics, 431, doi:10.1016/j.tecto.2006.05.038, 2007.

Balasis, G., Maus, S., Luehr, H., and Rother, M.: Wavelet analysis of CHAMP flux gate magnetometer data, in: Earth Observation with CHAMP, edited by: Reigber, C., Luhr, H., Schwintzer, P., and Wickert, J., 347-352, Springer, New York, 2005.

Balasis, G., Daglis, I. A., Kapiris, P., Mandea, M., Vassiliadis, D., and Eftaxias, K.: From pre-storm activity to magnetic storms: a transition described in terms of fractal dynamics, Ann. Geophys., 24, 3557-3567, doi:10.5194/angeo-24-3557-2006, 2006.

Balogh, A., Dunlop, M. W., Cowley, S. W. H., Southwood, D. J., Thomlinson, J. G., Glassmeier, K. H., Musmann, G., Luhr, H., Buchert, S., Acuna, M. H., Fairfield, D. H., Slavin, J. A., Riedler, W., Schwingenschuh, K., and Kivelson, M. G.: The Cluster Magnetic Field Investigation, Space Sci. Rev., 79, 6592, doi:10.1023/A:1004970907748, 1997.

Blanco-Cano, X., Omidi, N., and Russell, C. T.: Macrostructure of collisionless bow shocks: 2 . ULF waves in the foreshock and magnetosheath, J. Geophys. Res., 111, A10205, doi:10.1029/2005JA011421, 2006.

Bortnik, J., Cutler, J. W., Dunson, C., and Bleier, T. E.: An automatic wave detection algorithm applied to Pc1 pulsations, J. Geophys. Res., 112, A04204, doi:10.1029/2006JA011900, 2007.

Clausen, L. B. N., Yeoman, T. K., Fear, R. C., Behlke, R., Lucek, E. A., and Engebretson, M. J.: First simultaneous measurements of waves generated at the bow shock in the solar wind, the magnetosphere and on the ground, Ann. Geophys., 27, 357-371, doi:10.5194/angeo-27-357-2009, 2009.

Constantinescu, O. D., Glassmeier, K.-H., Décréau, P. M. E., Fränz, M., and Fornaçon, K.-H.: Low frequency wave sources in the outer magnetosphere, magnetosheath, and near Earth solar wind, Ann. Geophys., 25, 2217-2228, doi:10.5194/angeo-25-22172007, 2007.

Daglis, I. A.: The role of magnetosphere-ionosphere coupling in magnetic storm dynamics, in: Magnetic Storms, edited by: Tsurutani, B. T., Gonzalez, W. D., Kamide, Y., and Arballo, J. K., American Geophysical Union, Washington, D.C., 1997.

Daglis, I. A. and Axford, W. I.: Fast ionospheric response to enhanced activity in geospace: Ion feeding of the inner magnetotail, J. Geophys. Res., 101, 5047-5065, 1996.

Daglis, I. A., Livi, S., Sarris, E. T., and Wilken, B.: Energy density of ionospheric and solar wind origin ions in the near-Earth magnetotail during substorms, J. Geophys. Res., 99, 5691-5703, 1994.

Dent, Z. C., Mann, I. R., Goldstein, J., Menk, F. W., and Ozeke, L. G.: Plasmaspheric depletion, refilling, and plasmapause dynamics: A coordinated ground-based and IMAGE satellite study, J. Geophys. Res., 111, A03205, doi:10.1029/2005JA011046, 2006.

Engebretson, M., Glassmeier, K.-H., Stellmacher, M., Hughes, W. J., and Lühr, H.: The dependence of high-latitude Pc5 wave power on solar wind velocity and on the phase of highspeed solar wind streams, J. Geophys. Res., 103, 26271-26283, doi:10.1029/97JA03143, 1998.

Engebretson, M. J., Keiling, A., Fornacon, K.-H., Cattell, C. A., Johnson, J. R., Posch, J. L., Quick, S. R., Glassmeier, K.-H., Parks, G. K., and Rème, H.: Cluster observations of Pc 12 waves and associated ion distributions during the October and November 2003 magnetic storms, Planet. Space Sci., 55, 829848, doi:10.1016/j.pss.2006.03.015, 2007. 
Eriksson, P. T. I., Blomberg, L. G., Walker, A. D. M., and Glassmeier, K.-H.: Poloidal ULF oscillations in the dayside magnetosphere: a Cluster study, Ann. Geophys., 23, 2679-2686, doi:10.5194/angeo-23-2679-2005, 2005.

Escoubet, C. P., Schmidt, R., and Goldstein, M. L.: Cluster - Science and Mission Overview, Space Sci. Rev., 79, 11-32, 1997.

Fraser, B. J., Horwitz, J. L., Slavin, J. A., Dent, Z. C., and Mann, I. R.: Heavy ion mass loading of the geomagnetic field near the plasmapause and ULF wave implications, Geophys. Res. Lett., 32, L04102, doi:10.1029/2004GL021315, 2005.

Harnett, E. M., Winglee, R. M., Stickle, A., and Lu, G.: Prompt ionospheric/magnetospheric responses 29 October 2003 Halloween storm: Outflow and energization, J. Geophys. Res., 113, A06209, doi:10.1029/2007JA012810, 2008.

Heilig, B., Lühr, H., and Rother, M.: Comprehensive study of ULF upstream waves observed in the topside ionosphere by CHAMP and on the ground, Ann. Geophys., 25, 737-754, doi:10.5194/angeo-25-737-2007, 2007.

Horne, R. B., Thorne, R. M., Shprits, Y. Y., Meredith, N. P., Glauert, S. A., Smith, A. J., Kanekal, S. G., Baker, D. N., Engebretson, M. J., Posch, J. L., Spasojevic, M., Inan, U. S., Pickett, J. S., and Decreau, P. M. E.: Wave acceleration of electrons in the Van Allen radiation belts, Nature, 437, 7227-7230, doi:10.1038/nature03939, 2005.

Jacobs, J. A., Kato, Y., Matsushita, S., and Troitskaya, V. A.: Classification of geomagnetic micropulsations, J. Geophys. Res., 69, 180-181, 1964.

Jadhav, G., Rajaram, M., and Rajaram, R.: Modification of daytime compressional waves by the ionosphere: first results from Oersted, Geophys. Res. Lett., 28, 103-106, 2001.

Kepko, L., Spence, H. E., and Singer, H. J.: ULF waves in the solar wind as direct drivers of magnetospheric pulsations, Geophys. Res. Lett., 29, 1197, doi:10.1029/2001GL014405, 2002.

Kessel, R. L., Mann, I. R., Fung, S. F., Milling, D. K., and O'Connell, N.: Correlation of Pc5 wave power inside and outside themagnetosphere during high speed streams, Ann. Geophys., 22, 629-641, doi:10.5194/angeo-22-629-2004, 2004.

Kokubun, S., Yamamoto, T., Acuna, M. H., Hayashi, K., Shiokawa, K., and Kawano, H.: The GEOTAIL magnetic field experiment, J. Geomag. Geoelectr., 46, 7-21, 1994.

Lee, E. A., Mann, I. R., Loto'aniu, T. M., and Dent, Z. C.: Global Pc5 pulsations observed at unusually low $\mathrm{L}$ during the great magnetic storm of 24 March 1991, J. Geophys. Res., 112, A05208, doi:10.1029/2006JA011872, 2007.

Loto'aniu, T. M., Fraser, B. J., and Waters, C. L.: Propagation of electromagnetic ion cyclotron wave energy in the magnetosphere, J. Geophys. Res., 110, A07214, doi:10.1029/2004JA010816, 2005.

Loto'aniu, T. M., Mann, I. R., Ozeke, L. G., Chan, A. A., Dent, Z. C., and Milling, D. K.: Radial diffusion of relativistic electrons into the radiation belt slot region during the 2003 Halloween geomagnetic storms, J. Geophys. Res., 111, A04218, doi:10.1029/2005JA011355, 2006.

Mandea M. and Balasis, G.: The SGR 1806-20 magnetar signature on the Earth's magnetic field, Geophys. J. Int., doi:10.1111/j.1365-246X.2006.03125.x, see report http://www. sciencemag.org/content/vol314/issue5798/twil.dtl, 2006.

Menk, F.: Magnetospheric ULF Waves: A Review, in: "The Dynamic Magnetosphere", edited by: Liu, W. and Fujimoto, M.,
IAGA Special Sopron Book Series, Springer, 3, 223, 2011.

Miyashita, Y., Miyoshi, Y., Matsumoto, Y., Ieda, A., Kamide, Y., Nosé, M., Machida, S., Hayakawa, H., McEntire, R. W., Christon, S. P., Evans, D. S., and Troshichev, O. A.: Geotail observations of signatures in the near-Earth magnetotail for the extremely intense substorms of the 30 October 2003 storm, J. Geophys. Res., 110, A09S25, doi:10.1029/2005JA011070, 2005.

Murphy, K. R., Rae, I. J., Mann, I. R., Milling, D. K., Watt, C. E. J., Ozeke, L., Frey, H. U., Angelopoulos, V., and Russell, C. T.: Wavelet-based ULF wave diagnosis of substorm expansion phase onset, J. Geophys. Res., 114, A00C16, doi:10.1029/2008JA013548, 2009.

Nosé, M., Iyemori, T., Takeda, M., Kamei, T., Milling, D. K., Orr, D., Singer, H. J., Worthington, E. W., and Sumitomo, N.: Automated detection of Pi2 pulsations using wavelet analysis: 1. Method and an application for substorm monitoring, Earth Planets Space, 50, 773-783, 1998.

Pickett, J. S., Grison, B., Omura, Y., Engebretson, M. J., Dandouras, I., Masson, A., Adrian, M. L., Santolik, O., Decreau, P. M. E., Cornilleau-Wehrlin, N., and Constantinescu, D.: Cluster observations of EMIC triggered emissions in association with Pc1 waves near Earth's plasmapause, Geophys. Res. Lett., 37, L09104, doi:10.1029/2010GL042648, 2010.

Pilipenko, V., Kozyreva, O., Belakhovsky, V., Engebretson, M. J., and Samsonov, S.: Generation of magnetic and particle Pc5 pulsations during the recovery phase of strong magnetic storms, Proc. R. Soc. A, 466, 3363-3390, 2010.

Rae, I. J., Donovan, E. F., Mann, I. R., Fenrich, F. R., Watt, C. E. J., Milling, D. K., Lester, M., Lavraud, B., Wild, J. A., Singer, H. J., Rème, H., and Balogh, A.: Evolution and characteristics of global Pc5 ULF waves during a high solar wind speed interval, J. Geophys. Res., 110, A12211, doi:10.1029/2005JA011007, 2005.

Reigber, C., Lühr, H., Schwintzer, P., and Wickert, J. (Eds.): Earth Observation with CHAMP: Results from Three Years in Orbit, pp. 628, Springer, 2005.

Sakurai, T. and Tonegawa, Y.: Extreme magnetic field variations during the October 2003 superstorm, Adv. Polar Upper Atmos. Res., 19, 21-41, 2005.

Sakurai, T., Tonegawa, Y., Kitagawa, T., Yumoto, K., Yamomoto, T., Kokubun, S., Mukai, T., and Tsuruda, T.: Dayside magnetopause Pc3 and Pc5 ULF waves observed by the GEOTAIL satellite, Earth Planets Space, 51, 965-978, 1999.

Samson, J. C., Harrold, B. G., Ruohoniemi, J. M., Greenwald, R. A., and Walker, A. D. M.: Field line resonances associated with MHD waveguides in the magnetosphere, Geophys. Res. Lett., 25, 3701-3704, 1992.

Sarris, T. E., Liu, W., Kabin, K., Li, X., Elkington, S. R., Ergun, R., Rankin, R., Angelopoulos, V., Bonnell, J., Glassmeier, K. H., and Auster, U.: Characterization of ULF pulsations by THEMIS, Geophys. Res. Lett., 36, L04104, doi:10.1029/2008GL036732, 2009.

Sarris, T. E., Liu, W., Li, X., Kabin, K., Talaat, E. R., Rankin, R., Angelopoulos, V., Bonnell, J., and Glassmeier, K.-H.: THEMIS observations of the spatial extent and pressure-pulse excitation of field line resonances, Geophys. Res. Lett., 37, L15104, doi:10.1029/2010GL044125, 2010.

Schäfer, S., Glassmeier, K. H., Eriksson, P. T. I., Pierrard, V., Fornaçon, K. H., and Blomberg, L. G.: Spatial and temporal characteristics of poloidal waves in the terrestrial plasmas- 
phere: a CLUSTER case study, Ann. Geophys., 25, 1011-1024, doi:10.5194/angeo-25-1011-2007, 2007.

Southwood, D. J. and Kivelson, M. G.: The magnetohydrodynamic response of the magnetospheric cavity to changes in solar wind pressure, J. Geophys. Res., 95, 2301-2309, doi:10.1029/JA095iA03p02301, 1990.

Stolle, C., Lühr, H., Rother, M., and Balasis, G.: Magnetic signatures of equatorial spread $\mathrm{F}$ as observed by the CHAMP satellite, J. Geophys. Res., 111, A02304, doi:10.1029/2005JA011184, 2006.

Takahashi, K. and Anderson, B.: Distribution of ULF Energy $(f<$ $80 \mathrm{mHz}$ ) in the Inner Magnetosphere: A Statistical Analysis of AMPTE CCE Magnetic Field Data, J. Geophys. Res., 97, 1075110773, 1992.

Thorne, R. M. and Horne, R. B.: Modulation of electromagnetic ion cyclotron instability due to interaction with ring current $\mathrm{O}+$ during magnetic storms, J. Geophys. Res., 102, 14155-14163, 1997.

Torrence, C. and Compo, G. P.: A Practical Guide to Wavelet Analysis, Bull. Am. Meteor. Soc., 79, 61-78, 1998.

Ukhorskiy, A. Y., Sitnov, M. I., Takahashi, K., and Anderson, B. J.: Radial transport of radiation belt electrons due to stormtime Pc5 waves, Ann. Geophys., 27, 2173-2181, doi:10.5194/angeo27-2173-2009, 2009.
Usanova, M. E., Mann, I. R., Rae, I. J., Kale, Z. C., Angelopoulos, V., Bonnell, J. W., Glassmeier, K.-H., Auster, H. U., and Singer, H. J.: Multipoint observations of magnetospheric compressionrelated EMIC Pc1 waves by THEMIS and CARISMA, Geophys. Res. Lett., 35, L17S25, doi:10.1029/2008GL034458, 2008.

Wang, Y., Fu, S., Zong, Q., Yang, B., Pu, Z., Xie, L., and Zhou, X.: Multi-spacecraft observations of ULF waves during the recovery phase of magnetic storm on October 30, 2003, Sci. China Ser. E-Tech. Sci., 51, 1772-1785, 2008.

Zong, Q.-G., Zhou, X.-Z., Li, X., Song, P., Fu, S. Y., Baker, D. N., Pu, Z. Y., Fritz, T. A., Daly, P., Balogh, A., and Rème, H.: Ultralow frequency modulation of energetic particles in the dayside magnetosphere, Geophys. Res. Lett., 34, L12105, doi:10.1029/2007GL029915, 2007.

Zong, Q.-G., Zhou, X.-Z., Wang, Y. F., Li, X., Song, P., Baker, D. N., Fritz, T. A., Daly, P. W., Dunlop, M., and Pedersen, A.: Energetic electron response to ULF waves induced by interplanetary shocks in the outer radiation belt, J. Geophys. Res., 114, A10204, doi:10.1029/2009JA014393, 2009. 